\title{
Identification of hub genes associated with prognosis, diagnosis, immune infiltration and therapeutic drug in liver cancer by integrated analysis
}

Xinyi Lei ${ }^{1}$, Miao Zhang ${ }^{2}$, Bingsheng Guan ${ }^{1}$, Qiang Chen ${ }^{3}$, Zhiyong Dong ${ }^{1 *}$ and Cunchuan Wang ${ }^{1 *}$ (D)

\begin{abstract}
Background: Liver cancer is one of the most common cancers and causes of cancer death worldwide. The objective was to elucidate novel hub genes which were benefit for diagnosis, prognosis, and targeted therapy in liver cancer via integrated analysis.

Methods: GSE84402, GSE101685, and GSE112791 were filtered from the Gene Expression Omnibus (GEO). Differentially expressed genes (DEGs) were identified by using the GEO2R. The GO and KEGG pathway of DEGs were analyzed in the DAVID. PPI and TF network of the DEGs were constructed by using the STRING, TRANSFAC, and Harmonizome. The relationship between hub genes and prognoses in liver cancer was analyzed in UALCAN based on The Cancer Genome Atlas (TCGA). The diagnostic value of hub genes was evaluated by ROC. The relationship between hub genes and tumor-infiltrate lymphocytes was analyzed in TIMER. The protein levels of hub genes were verified in HPA. The interaction between the hub genes and the drug were identified in DGldb.

Results: In total, 108 upregulated and 60 downregulated DEGs were enriched in 148 GO terms and 20 KEGG pathways. The mRNA levels and protein levels of CDK1, HMMR, PTTG1, and TTK were higher in liver cancer tissues compared to normal tissues, which showed excellent diagnostic and prognostic value. CDK1, HMMR, PTTG1, and TTK were positively correlated with tumor-infiltrate lymphocytes, which might involve tumor immune response. The CDK1, HMMR, and TTK had close interaction with anticancer agents.

Conclusions: The CDK1, HMMR, PTTG1, and TTK were hub genes in liver cancer; hence, they might be potential biomarkers for diagnosis, prognosis, and targeted therapy of liver cancer.
\end{abstract}

Keywords: Liver cancer, Hub gene, Prognosis, Diagnosis, Immune infiltration, Therapeutic drug

\footnotetext{
*Correspondence: dongzy2008@jnu.edu.cn; twcc2015@163.com

${ }^{1}$ Department of Gastrointestinal Surgery, the First Affiliated Hospital of Jinan University, No.613 Huangpu Road West, Guangzhou 510630, China

Full list of author information is available at the end of the article
}

(c) The Author(s). 2021 Open Access This article is licensed under a Creative Commons Attribution 4.0 International License, which permits use, sharing, adaptation, distribution and reproduction in any medium or format, as long as you give appropriate credit to the original author(s) and the source, provide a link to the Creative Commons licence, and indicate if changes were made. The images or other third party material in this article are included in the article's Creative Commons licence, unless indicated otherwise in a credit line to the material. If material is not included in the article's Creative Commons licence and your intended use is not permitted by statutory regulation or exceeds the permitted use, you will need to obtain permission directly from the copyright holder. To view a copy of this licence, visit http://creativecommons.org/licenses/by/4.0/. The Creative Commons Public Domain Dedication waiver (http://creativecommons.org/publicdomain/zero/1.0/) applies to the data made available in this article, unless otherwise stated in a credit line to the data. 


\section{Highlights of our study}

(1) Three gene expression profiles (GSE84402, GSE101685, and GSE112791) were combined, for the first time, for integrated analysis in gene expression omnibus (GEO).

(2) We revealed the interrelationship between the CDK1, HMMR, PTTG1, TTK, and immune infiltration.

(3) CDK1, HMMR, PTTG1, and TTK could be identified as the novel biomarkers for prognosis and diagnosis in liver cancer.

(4) We demonstrated the interaction between the CDK1, HMMR, TTK, and new types of anticancer agents and traditional chemotherapy drugs.

\section{Introduction}

In the most common malignant tumor, liver cancer is one of the most common cancers and causes of cancer death worldwide, especially in China [1]. Liver cancer includes two histological types of malignant tumors: hepatocellular carcinoma (HCC) and intrahepatic cholangiocarcinoma (ICC) [2]. More than 840,000 new cases of liver cancer occurred in addition to 781,000 deaths in 2018, which had become a severe public health issue [3]. Liver cancer is mainly caused by the hepatitis $B$ virus (HBV) and the hepatitis C virus (HCV) [4]. Meanwhile, aflatoxin, algal hepatoxins, betel nut, alcohol, and tobacco have been reported as potential risk factors of liver cancer $[5,6]$.

A comprehensive understanding of the occurrence, development, and metastasis of liver cancer will be beneficial for early diagnosis and precise treatment of patients. The immune checkpoint inhibitor (ICI) therapy targeting cytotoxic T-lymphocyte-associated protein-4 (CTLA-4), anti-programmed cell death protein-1 (PD-1), and programmed cell death-ligand 1 (PD-L1) were potential activity against $\mathrm{HCC}$ and manageable safety in clinical trial [7]. The molecular ablation of 3phosphoinositide-dependent protein kinase-1 function can improve the susceptibility of HCC cells to be resistant to radiotherapy, which is related to deactivated PI3K/AKT/mTOR signaling way [8]. Recent meta-analysis has revealed that circulating tumor DNA (ctDNA) can serve as an assistant tool when combined with alphafetoprotein (AFP) for HCC detection [9]. The latest sequence studies have revealed that the special non-coding RNA, such as lncRNA NEAT1, lncRNA FLJ33360, lncRNA FOXD3-AS1, and lncRNA LEF1-AS1 are associated with liver cancer [10-13].

With the deepening understanding of epidemiology, etiology, and molecular biology of liver cancer, the regimens currently available were still unsatisfactory. Early diagnosis and precise treatment of liver cancer is still a huge challenge. Microarray technology has been widely used to detect the expression of genes in animals and humans, and it can also be helpful in exploring the change of gene expression during tumor occurrence and development. However, it is very difficult to acquire convincing results with the only one gene microarray analysis. In our study, three gene expression profiles (GSE84402, GSE101685, and GSE112791) were combined, for the first time, for integrated analysis in Gene Expression Omnibus (GEO). The differentially expressed genes (DEGs) were identified in liver cancer tissues compared to normal liver tissues. A large number of biomarkers have been identified in liver cancer; however, most of the biomarkers are directly experimental and not prospectively evaluated. In our research, Gene Ontology (GO) and Kyoto Encyclopedia of Genes and Genomes (KEGG) pathway analysis of DEGs were analyzed in the Database for Annotation, Visualization, and Integrated Discovery (DAVID). The protein-protein interaction (PPI) network was built by using the STRI NG database and cytoscape software to extract the hub genes and significant module. The transcription factors (TF) network was constructed by using the TRANSFAC, Harmonizome database, and cytoscape software. The prognostic roles of hub genes were verified in The Cancer Genome Atlas (TCGA) by using the UALCAN. The diagnostic value of hub genes in distinguishing between liver cancer tissues and normal liver tissues were analyzed by using the receiver operating characteristic (ROC) curve. The correlations between the hub genes and tumor-infiltrate lymphocytes were analyzed in the Tumor IMmune Estimation Resource (TIMER). The protein levels of hub genes were verified in the Human Protein Atlas (HPA). The interactions between hub genes and related therapeutic drugs were explored through the drug-gene interaction database (DGIdb). The hub genes might be targeted therapeutically or prioritized for drug progress. Due to a single database and few samples, the inconsistent results might appear. All our results were obtained from the multi-database which included sufficient samples to overcome the disadvantages. Our objective is to provide further understanding of the etiopathogenesis of liver cancer and identify the novel diagnostic indicators, prognostic markers, and precise target drug points by integrated analysis.

\section{Material and methods Data extraction}

In total, three gene expression profiles (GSE84402, GSE101685, and GSE112791) were filtered from the Gene Expression Omnibus (GEO https:// www.ncbi.nlm. nih.gov/geo). As a free public genome, GEO database was utilized for storing array data and sequence data. The GSE84402 contained 14 liver cancer tissues and 14 
matched corresponding non-cancerous liver tissues [14]. The GSE101685 included 24 liver cancer tissues and 8 normal liver tissues. The GSE112791 covered 15 normal liver tissues and 183 liver cancer tissues [15].

\section{Data processing}

The differentially expressed genes (DEGs) between liver cancer tissues and normal liver tissues of GSE84402, GSE101685, and GSE112791 were screened out by using GEO2R (https://www.ncbi.nlm.nih.gov/geo/geo2r), respectively. The GEO2R is an interactive online tool based on the $\mathrm{R}$ programming language and is used for screening DEGs from the gene expression profiles between liver cancer tissues and normal liver tissues. The adjusted $P$ value (adjust $P$ ) $<0.05$ and $\mid \log _{2}$ fold change $\mid>2$ were used to identify DEGs. The DEGs that were consistently expressed in three datasets were screened out.

\section{Analysis of functional and pathway enrichment}

The Database for Annotation, Visualization and Integrated Discovery (DAVID version $6.8 \mathrm{https}$ ://david. ncifcrf.gov/tools.jsp) was used for analyzing the Gene Ontology (GO) and the Kyoto Gene and Genome Encyclopedia (KEGG) pathway of DEGs [16, 17]. $P<0.05$ was set as the cut-off criterion.

\section{Analysis of PPI network and TF network}

The STRING (version 11.0 https://string-db.org) was utilized to analyze the functional interaction of DEGs [18]. The score of confidence $>0.7$ was considered as significant value. The cytoscape (version 3.7.1) was used to build Protein-Protein interaction (PPI) network. The parameter settings were as follows: degree cutoff $=2$, node score cutoff $=0.2$, $\mathrm{k}$-score $=2$, maximum depth $=$ 100 [19]. The degree of genes $>10$ were considered as hub genes. The significant module was screened by Molecular Complex Detection (MCODE). The curated transcription factor (TF) targets of DEGs were obtained from the TRANSFAC (http://gene-regulation.com/pub/ databases.html) [20, 21] and Harmonizome database (https://maayanlab.cloud/Harmonizome/) [22]. The cytoscape software (version 3.7.1) was used to build TF network. The Fisher's exact test was used to perform the enrichment analyses of DEGs. $P<0.05$ was set as the cutoff criterion. The $P$ values were adjusted for multiple testing by the Bonferroni method.

\section{Verification and survival analysis of hub genes}

The expression levels and survival analysis of hub genes were analyzed by using the UALCAN (http://ualcan. path.uab.edu/) which is a tool for analysis data from The Cancer Genome Atlas (TCGA) [23]. Based on transcripts per million (TPM) of hub genes, the data of liver cancer patients was divided into two groups. The high group's TPM was higher than the upper quartile. The low/medium group's TPM was lower than the upper quartile. The Kaplan-Meier and log-rank test were utilized for survival analysis. $P<0.05$ was set as the cut-off criterion. UALCAN was used to screen hub genes with potential prognostic value for subsequent analysis.

\section{Verification of hub genes by ROC analysis}

The expression levels of hub genes with potential prognostic value were used for receiver operating characteristic (ROC) analysis to evaluate their diagnostic value to distinguish between liver cancer tissues and normal liver tissues in internal set (GSE84402) and an independent external set (GSE14520). The GSE14520 covered 21 normal liver tissues and 22 liver cancer tissues [24-30]. ROC analysis was performed in RStudio by pROC package [31]. The hub genes with area under curve (AUC) > 0.8 as well as $P<0.05$ were set as the cut-off criterion.

\section{Immune infiltrates analysis of hub genes}

Tumor IMmune Estimation Resource (TIMER, https:// cistrome.shinyapps.io/timer/) was used to analyze the immune infiltrates across different types of cancer [32]. TIMER can analyze the abundance of immune cells from the gene expression in cancer samples. By applying the deconvolution method, TIMER was used to analyze the relationship between the infiltrating level of immune cells and the potential prognostic hub gene in liver cancer. The correlation between the potential prognostic hub genes and the gene markers for immune cell infiltration was performed through related modules. The relationship between somatic copy number alterations (SCNA) of the potential prognostic hub genes and infiltrating immune cells were explored via related modules. $P<0.05$ was set as the cut-off criterion.

\section{Immunohistochemical analysis of hub genes in HPA}

The protein levels of the potential prognostic hub gene in liver cancer tissues and normal liver tissues were extracted from the Human Protein Atlas (HPA, https:// www.ptroteinatlas.org/) which contained the data of immunohistochemistry expression for human tissues [33]. The levels of expression were divided into four groups: high, medium, low, and not detected via the score system, which included the proportion of stained cells $(>75 \%, 25-75 \%$, or $<25 \%)$ and the intensity of staining (strong, moderate, weak, or negative).

\section{Drug-gene interaction analysis of hub genes}

The potential prognostic hub genes were supposed as the promising drug targets for searching drugs through the Drug-Gene Interaction database (DGIdb, version 4. 0.2-sha1 afd9f30b, https://dgidb.genome.wustl.edu/) [34]. 
The DGIdb consists of the drug-gene interaction data from the Drug Bank, ChEMBL, NCBI Entrez, Ensembl, PharmGKB, PubChem, clinical trial, and literature in PubMed, which can help researchers mine existing data and generate assumptions about how genes may be targeted therapeutically or prioritized for drug development [35]. The cytoscape (version 3.7.1) was applied to perform the drug-gene interaction network.

\section{Results}

\section{Identification of DEGs in liver cancer}

In total, 455, 425, and 291 DEGs were extracted from the GSE84402, GSE101685, and GSE112791 datasets, respectively. In total, 168 DEGs were consistently expressed in the three datasets (Fig. 1), and they included 60 upregulated DEGs and 108 downregulated DEGs (Table 1).

\section{GO analysis and KEGG pathway of DEGs in liver cancer} The GO and KEGG pathway of DEGs was performed by using the DAVID 6.8. The DEGs were divided into biological process groups, molecular function groups, cellular components groups, and KEGG pathway groups. The GO terms and KEGG pathways were ranked by $-\log _{10}(P$ value). Top 5 GO terms and KEGG pathways were selected according to $-\log _{10}(P$ value). Figure 2 shows the top 5 GO terms and KEGG pathways for upregulated DEGs (Fig. 2a) and downregulated DEGs (Fig. 2b).

\section{PPI network and significant module analysis in liver cancer}

In total, 100 genes (score of confidence >0.7) in 168 DEGs were filtered into the PPI network. The PPI network included 100 nodes and 738 sides. It consisted of 47 upregulated genes and 53 downregulated genes (Fig. 3a). In total, 41 genes (degree $>10$ ) were considered as hub genes (Table 1, in bold). The characteristics of hub genes are shown in Table 2, which consisted of degree, betweenness centrality, closeness centrality, clustering coefficient, stress, and average shortest path length. The significant module was chosen from the PPI

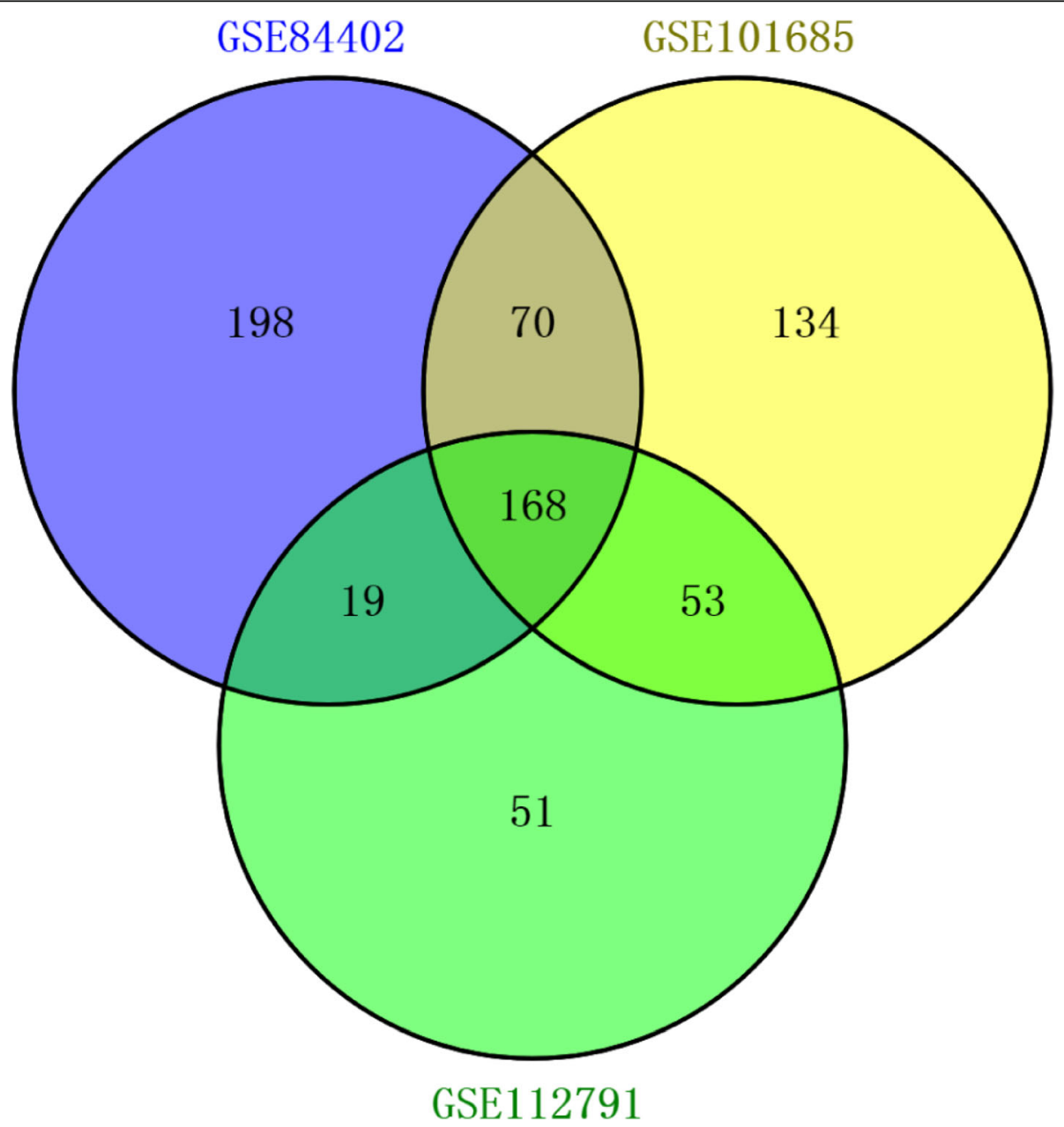

Fig. 1 Identification of differentially expression genes (DEGs) in three mRNA expression profiles 
Table 1 DEGs in liver cancer samples compared with normal samples

\begin{tabular}{|c|c|}
\hline EGs & Gene name \\
\hline oregulated & $\begin{array}{l}\text { CCNB1, CDKN3, CCNB2, ASPM, TOP2A, UBE2T, BIRC5, FAM83D, MDK, KIF4A, CDK1, FAM72A///FAM72D///FAM72B///FAM72C, TTK, } \\
\text { ANLN, CENPF, NCAPG, PBK, PTTG1, AURKA, RACGAP1, GPC3, NUF2, PRC1, GINS1, GMNN, RRM2, MELK, NEK2, CDC20, IQGAP3, } \\
\text { NDC80, DLGAP5, ECT2, HMMR, KIF2OA, SULT1C2, RAD51AP1, IGF2BP3, CENPK, DTL, DUXAP10, HELLS, FLVCR1, TYMS, CAP2, MAD2L1, } \\
\text { UHRF1, KIAA0101, MCM6, PRR11, BUB1B, ACSL4, PEG10, CRNDE, ROBO1, SLC35F6///CENPA, CD24, CTHRC1, CKAP2, RBM24. }\end{array}$ \\
\hline ownregulated & $\begin{array}{l}\text { CLEC4M, CLEC4G, OIT3, FCN3, CYP2A6, TTC36, FOSB, CYP1A2, APOF, FOS, FCN2, MT1G, GLS2, GBA3, LCAT, CLEC1B, KCNN2, CXCL14, GLYAT, } \\
\text { HGF, MARCO, CYP39A1, MT1X, GPM6A, HHIP, ANXA10, C8A, MT1M, TMEM27, GYS2, AKR1D1, HAMP, MT1F, PLAC8, CYP2B6, C7, KMO, MT1H, } \\
\text { NAT2, SLC22A1, CYP2A7, CNDP1, MT1HL1, C3P1, BCO2, CRHBP, MT1E, GSTZ1, KCND3, SORL1, HAO2, ADH1B, CYP4A11, EGR1, ESR1, } \\
\text { SLC25A47, CYP4A22/IICYP4A11, GNMT, HGFAC, LINCO1093, F9, SRPX, LINCO0844, HEPN1/IHEPACAM, SRD5A2, CYP2BTPIIICYP2B6, } \\
\text { MFSD2A, FLI22763, FOLH1, BBOX1, SDS, BCHE, C9, SLC10A1, TSLP, LYVE1, MME, PGLYRP2, DCN, CYP3A4, CYP8B1, KBTBD11, GHR, CTH, } \\
\text { CFHR4, AADAT, CXCL2, CYP26A1, C6, CETP, PDGFRA, FBP1, SERPINE1, RSPO3, PBLD, RDH16, SLCO1B3, IDO2, PZP, LPA, PCK1, AFM, ASPA, } \\
\text { CLRN3, CNTN3, HPGD, ACSM3, LOC101928916/IINNMT. }\end{array}$ \\
\hline
\end{tabular}

A total of 60 upregulated DEGs and 108 downregulated DEGs were identified in the liver cancer tissues, compared with normal liver tissues. The hub genes were shown in boldface

network by analysis of MCODE (Fig. 3b). The TF network comprised 9 DEGs and 3 TFs (Fig. 3c).

Verification and survival analysis of hub genes in liver cancer The UALCAN online was used for analyzing the expression of significant hub genes in TCGA between liver hepatocellular carcinoma samples and normal liver samples. The trend of expression of significant hub genes was similar to the results generated by GEO datasets (Fig. 4). Meanwhile, the association between the mRNA expression of significant hub genes and clinical characteristics of liver hepatocellular carcinoma patients was analyzed via using the UALCAN, including the patient's cancer stages and TP53 mutation status. The mRNA expression of CDK1, HMMR, PTTG1, and TTK were associated with advanced stages of liver hepatocellular carcinoma. Liver hepatocellular carcinoma patients who were with advanced cancer stages inclined to have the higher mRNA expression levels of CDK1, HMMR, PTTG1, and TTK (Fig. 4a-d). The expression levels of CDK1, HMMR, PTTG1, and TTK in stage 3 was higher than those in stage 4, which were attributed to the limited number of stage 4 patients (only six patients in stage 4). The higher mRNA expression levels of $C D K 1(P<$ $0.0001), H M M R(P<0.0001)$, PTTG1 $(P<0.0001)$, and TTK $(P<0.0001)$ were explored in liver hepatocellular carcinoma patients with TP53 mutation (Fig. 4e-h).

The survival analysis of liver hepatocellular carcinoma patients in TCGA were performed based on hub genes by using the UALCAN. The results revealed that high expression of CDK1 $(P<0.0001)$, HMMR $(P<0.0001)$, PTTG1 $(P<0.0001)$, and TTK $(P<0.0001)$ were associated with shorter overall survival rates (Fig. $5 \mathrm{a}-\mathrm{d}$ ). In summary, CDK1, HMMR, PTTG1, and TTK might be potential biomarkers to evaluate the prognosis of liver hepatocellular carcinoma patients.

\section{Verification of hub genes by ROC analysis}

To identify the diagnostic value of CDK1, HMMR, PTTG1, and TTK distinguishing between liver cancer tissues and normal liver tissues, ROC analysis was performed by utilizing the data of the internal set (GSE84402). As shown in Fig. 6a, the AUC was 0.95 ( $P$ $<0.0001)$ for $C D K 1,0.91(P<0.0001)$ for $H M M R, 0.93$ $(P<0.0001)$ for PTTG1, and 0.94 $(P<0.0001)$ for TTK. In the independent external set (GSE14520), the AUC was $0.98(P<0.0001)$ for $C D K 1,0.97(P<0.0001)$ for HMMR, $0.99(P<0.0001)$ for PTTG1, and $0.98(P<$ 0.0001) for TTK (Fig. 6b). Thus, the four hub genes might be potential diagnostic biomarker of liver cancer.

\section{Immune infiltrates analysis of hub genes}

The correlation between the mRNA expression of CDK1, HMMR, PTTG1, TTK, and infiltrating immune cells in liver cancer was analyzed by using the TIMER database. $C D K 1$ showed significant correlation with the abundance of B cell (cor $=0.469, P=2.97 \mathrm{e}-20)$, CD8+ $\mathrm{T}$ cell $($ cor $=0.316, P=2.38 \mathrm{e}-9), \mathrm{CD} 4+\mathrm{T}$ cell $($ cor $=$ $0.332, P=2.72 \mathrm{e}-10)$, macrophage $($ cor $=0.449, P=$ $2.60 \mathrm{e}-18$ ), neutrophil (cor $=0.344, P=4.98 \mathrm{e}-11$ ), and dendritic cell (cor $=0.442, P=1.17 \mathrm{e}-17$ ) (Fig. 7a). $H M M R$ showed significant correlation with the abundance of B cell (cor $=0.399, P=1.47 \mathrm{e}-14), \mathrm{CD} 8+\mathrm{T}$ cell (cor $=0.271, P=3.69 \mathrm{e}-7), \mathrm{CD} 4+\mathrm{T}$ cell $($ cor $=0.267, P$ $=4.91 \mathrm{e}-7)$, macrophage $($ cor $=0.351, P=2.54 \mathrm{e}-11)$, neutrophil (cor $=0.368, P=1.75 \mathrm{e}-12$ ), and dendritic cell (cor $=0.406, P=6.84 \mathrm{e}-15)$ (Fig. 7b). PTTG1 showed significant correlation with the abundance of B cell (cor $=0.429, P=7.86 \mathrm{e}-17), \mathrm{CD} 8+\mathrm{T}$ cell $($ cor $=0.326, P=$ 6.25e-10), CD4 $+\mathrm{T}$ cell $($ cor $=0.182, P=6.93 \mathrm{e}-4)$, macrophage (cor $=0.348, P=3.75 \mathrm{e}-11$ ), neutrophil (cor $=0.253, P=1.87 \mathrm{e}-6)$, and dendritic cell (cor $=0.381, P$ $=3.55 \mathrm{e}-13)$ (Fig. 7c). TTK showed significant correlation with the abundance of $\mathrm{B}$ cell (cor $=0.464, P=9.19 \mathrm{e}$ $-20)$, CD8 $+\mathrm{T}$ cell (cor $=0.313, P=3.27 \mathrm{e}-9)$, CD $4+\mathrm{T}$ cell (cor $=0.308, P=5.53 \mathrm{e}-9)$, macrophage $($ cor $=0.422$, $P=3.48 \mathrm{e}-16)$, neutrophil (cor $=0.355, P=1.16 \mathrm{e}-11$ ), and dendritic cell (cor $=0.424, P=2.92 \mathrm{e}-16)($ Fig. $7 \mathrm{~d})$. These results provided strong evidence that $C D K 1$, $H M M R$, PTTG1, and TTK played crucial roles for 


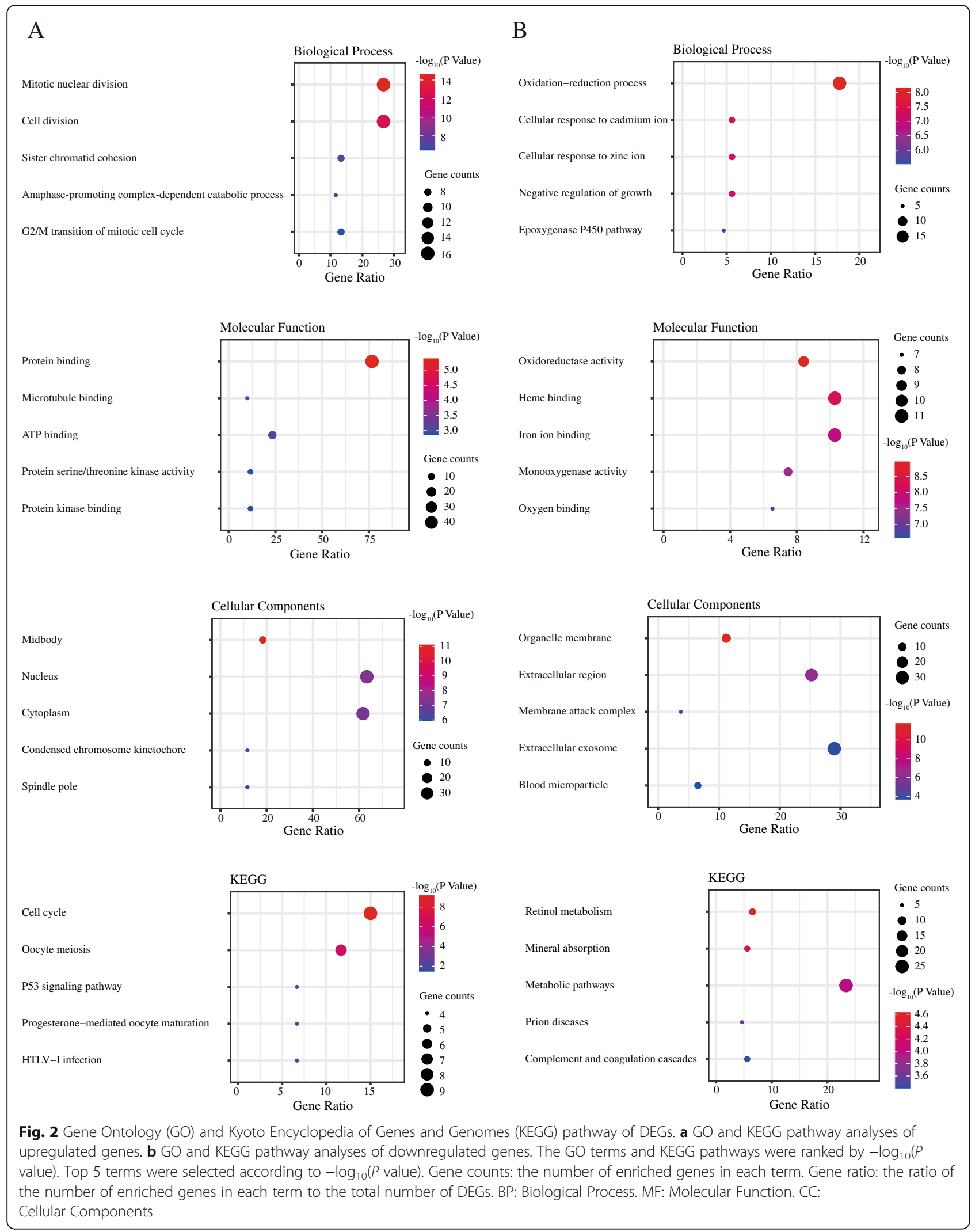




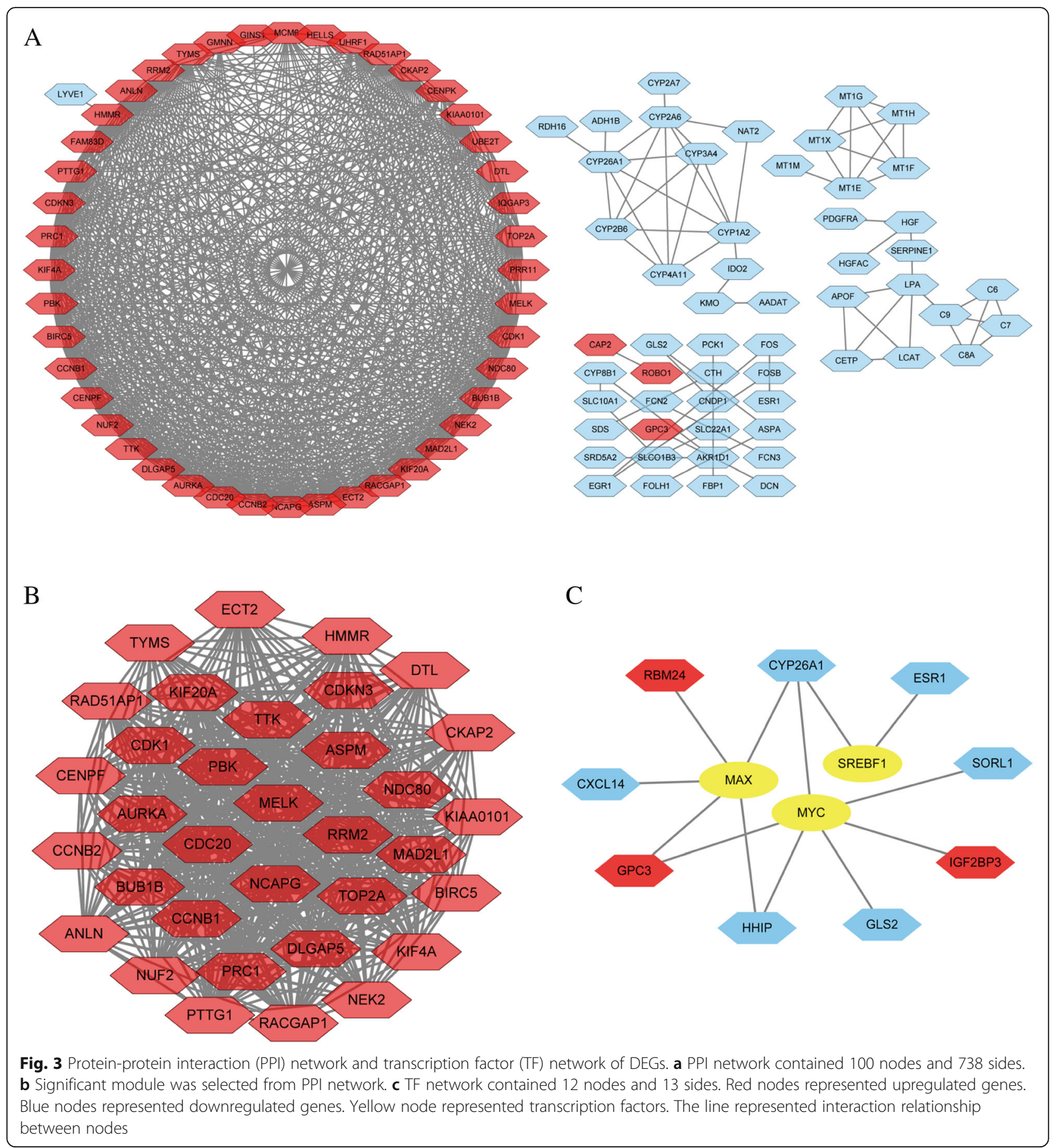

infiltrating immune cells, including $\mathrm{B}$ cells, CD8+ T cells, CD4+ T cells, macrophages, neutrophils, and dendritic cells.

The somatic copy number alterations (SCNA) included deep deletion, arm-level deletion, diploid/normal, arm-level gain, and high amplification. Furthermore, the relationship between SCNA of the CDK1, HMMR, PTTG1, and TTK and infiltrating immune cells in liver cancer was explored via using TIMER. These results showed that the copy number alterations (CNA) of $C D K 1$ had significant correlation with the infiltrating levels of B cells and CD4+ T cells (Fig. 8a); the CNA of $H M M R$ had significant correlation with the infiltrating levels of CD4+ T cells, macrophages, and neutrophils (Fig. 8b); the CNA of PTTG1 had significant correlation with the infiltrating levels of B cells, CD8+ $\mathrm{T}$ cells, CD4+ $\mathrm{T}$ cells, macrophages, neutrophils and dendritic cells (Fig. 8c); the CNA of TTK had significant 
Table 2 The topology properties of 41 hub genes (The genes are ranked by degree)

\begin{tabular}{|c|c|c|c|c|c|c|}
\hline Genes & Degree & $\begin{array}{l}\text { Betweenness } \\
\text { centrality }\end{array}$ & $\begin{array}{l}\text { Closeness } \\
\text { centrality }\end{array}$ & $\begin{array}{l}\text { Clustering } \\
\text { coefficient }\end{array}$ & Stress & $\begin{array}{l}\text { Average shortest } \\
\text { path length }\end{array}$ \\
\hline CDC20 & 41 & 4.09E-02 & $9.36 \mathrm{E}-01$ & $7.48 \mathrm{E}-01$ & 446 & 1.07 \\
\hline CDK1 & 40 & $2.89 \mathrm{E}-02$ & 9.17E-01 & 7.79E-01 & 398 & 1.09 \\
\hline TOP2A & 40 & $3.73 \mathrm{E}-02$ & 9.17E-01 & 7.67E-01 & 394 & 1.09 \\
\hline$B \cup B 1 B$ & 39 & $1.65 \mathrm{E}-02$ & 8.98E-01 & 7.99E-01 & 320 & 1.11 \\
\hline CCNB2 & 39 & $1.06 \mathrm{E}-02$ & 8.98E-01 & 8.19E-01 & 284 & 1.11 \\
\hline NCAPG & 39 & $2.64 \mathrm{E}-02$ & 8.98E-01 & 7.96E-01 & 354 & 1.11 \\
\hline ASPM & 39 & $1.50 \mathrm{E}-02$ & 8.98E-01 & 8.08E-01 & 302 & 1.11 \\
\hline AURKA & 38 & $8.26 \mathrm{E}-03$ & $8.80 \mathrm{E}-01$ & $8.45 \mathrm{E}-01$ & 232 & 1.14 \\
\hline MAD2L1 & 38 & 7.61E-03 & $8.80 \mathrm{E}-01$ & $8.48 \mathrm{E}-01$ & 224 & 1.14 \\
\hline CCNB1 & 38 & 7.61E-03 & $8.80 \mathrm{E}-01$ & $8.48 \mathrm{E}-01$ & 224 & 1.14 \\
\hline DLGAP5 & 37 & $9.50 \mathrm{E}-02$ & $8.63 \mathrm{E}-01$ & $8.45 \mathrm{E}-01$ & 216 & 1.16 \\
\hline KIF20A & 37 & $1.05 \mathrm{E}-02$ & $8.63 \mathrm{E}-01$ & $8.54 \mathrm{E}-01$ & 211 & 1.16 \\
\hline PBK & 37 & 5.79E-03 & 8.63E-01 & 8.74E-01 & 180 & 1.16 \\
\hline CENPF & 37 & 1.16E-02 & $8.63 \mathrm{E}-01$ & $8.44 \mathrm{E}-01$ & 222 & 1.16 \\
\hline RRM2 & 37 & $5.51 \mathrm{E}-03$ & 8.63E-01 & $8.75 \mathrm{E}-01$ & 174 & 1.16 \\
\hline MELK & 37 & $6.29 \mathrm{E}-03$ & $8.63 \mathrm{E}-01$ & $8.72 \mathrm{E}-01$ & 178 & 1.16 \\
\hline NDC80 & 36 & 4.01E-03 & $8.46 \mathrm{E}-01$ & 8.98E-01 & 134 & 1.18 \\
\hline PTTG1 & 35 & $3.72 \mathrm{E}-03$ & 8.30E-01 & $9.08 \mathrm{E}-01$ & 116 & 1.20 \\
\hline BIRC5 & 35 & $3.14 \mathrm{E}-03$ & 8.30E-01 & $9.18 \mathrm{E}-01$ & 102 & 1.20 \\
\hline$\pi K$ & 35 & $2.84 \mathrm{E}-03$ & 8.30E-01 & $9.23 \mathrm{E}-01$ & 96 & 1.20 \\
\hline$P R C 1$ & 35 & $2.20 \mathrm{E}-03$ & 8.30E-01 & $9.29 \mathrm{E}-01$ & 88 & 1.20 \\
\hline$H M M R$ & 35 & 4.80E-02 & 8.30E-01 & $9.81 \mathrm{E}-01$ & 350 & 1.20 \\
\hline KIAA0101 & 35 & $5.88 \mathrm{E}-03$ & 8.30E-01 & 8.81E-01 & 148 & 1.20 \\
\hline DTL & 35 & $6.38 \mathrm{E}-03$ & 8.30E-01 & $8.74 \mathrm{E}-01$ & 158 & 1.20 \\
\hline NEK2 & 34 & 3.29E-03 & $8.15 \mathrm{E}-01$ & $9.20 \mathrm{E}-01$ & 96 & 1.23 \\
\hline NUF2 & 34 & $2.92 \mathrm{E}-03$ & $8.15 \mathrm{E}-01$ & $9.20 \mathrm{E}-01$ & 94 & 1.23 \\
\hline CDKN3 & 34 & 3.07E-03 & $8.15 \mathrm{E}-01$ & $9.23 \mathrm{E}-01$ & 90 & 1.23 \\
\hline RACGAP1 & 33 & $9.43 \mathrm{E}-04$ & 8.00E-01 & $9.62 \mathrm{E}-01$ & 42 & 1.25 \\
\hline KIF4A & 33 & $2.22 \mathrm{E}-03$ & $8.00 \mathrm{E}-01$ & $9.45 \mathrm{E}-01$ & 62 & 1.25 \\
\hline RAD51AP1 & 32 & 7.50E-04 & 7.86E-01 & $9.68 \mathrm{E}-01$ & 34 & 1.27 \\
\hline ECT2 & 31 & $2.28 \mathrm{E}-04$ & 7.72E-01 & 9.87E-01 & 12 & 1.30 \\
\hline ANLN & 31 & 2.20E-04 & 7.72E-01 & 9.87E-01 & 12 & 1.30 \\
\hline TYMS & 30 & 1.19E-03 & 7.59E-01 & $9.52 \mathrm{E}-01$ & 46 & 1.32 \\
\hline CKAP2 & 27 & 0.00 & $7.21 \mathrm{E}-01$ & 1.00 & 0 & 1.39 \\
\hline MCM6 & 25 & $1.14 \mathrm{E}-02$ & $6.88 \mathrm{E}-01$ & 8.30E-01 & 130 & 1.45 \\
\hline UHRF1 & 19 & 1.07E-03 & $6.29 \mathrm{E}-01$ & $9.36 \mathrm{E}-01$ & 22 & 1.60 \\
\hline UBE2T & 19 & 0.00 & $6.29 \mathrm{E}-01$ & 1.00 & 0 & 1.60 \\
\hline CENPK & 14 & 0.00 & 5.87E-01 & 1.00 & 0 & 1.70 \\
\hline GMNN & 13 & $9.00 \mathrm{E}-05$ & 5.79E-01 & $9.74 \mathrm{E}-01$ & 4 & 1.73 \\
\hline FAM83D & 12 & 0.00 & 5.71E-01 & 1.00 & 0 & 1.75 \\
\hline HELLS & 11 & $2.63 \mathrm{E}-04$ & 5.64E-01 & $9.09 \mathrm{E}-01$ & 10 & 1.77 \\
\hline
\end{tabular}


A Expression of CDK1 in LIHC on cancer stages

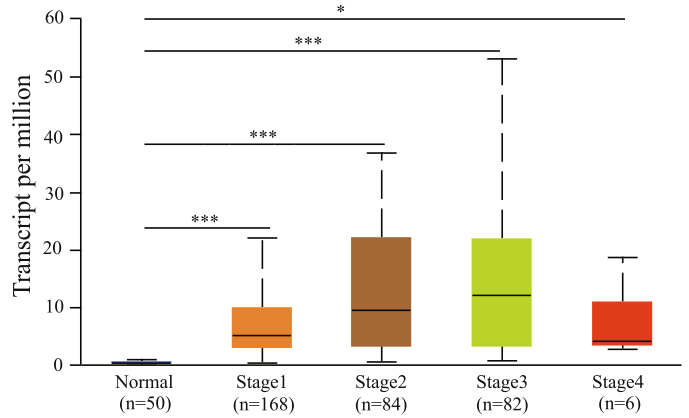

C

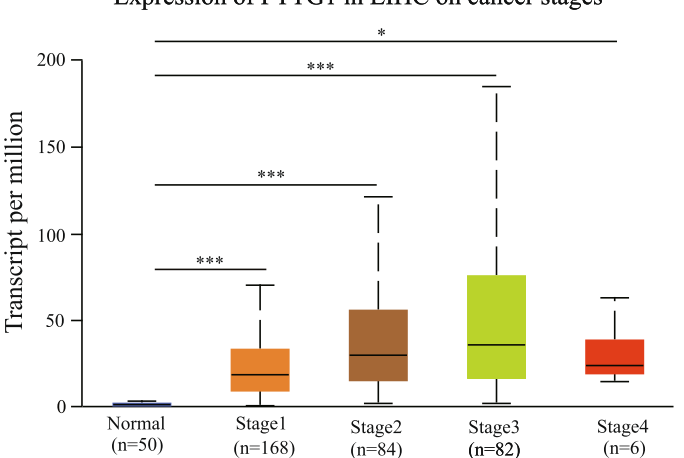

E

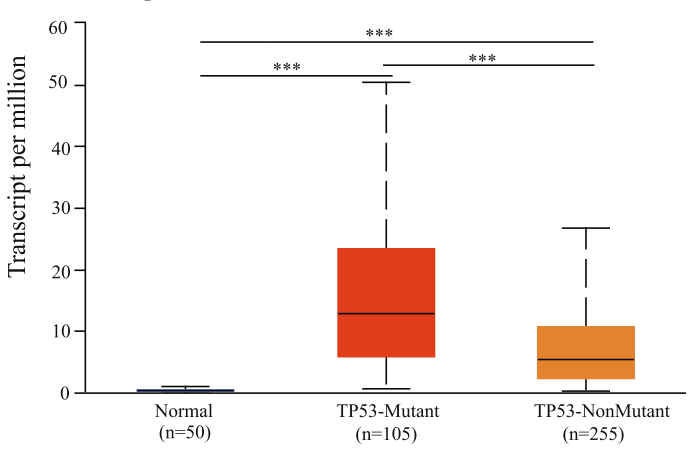

B Expression of HMMR in LIHC on cancer stages

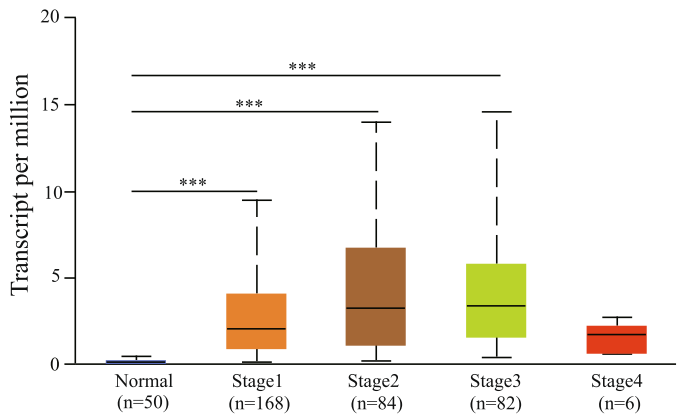

$\mathrm{D}$

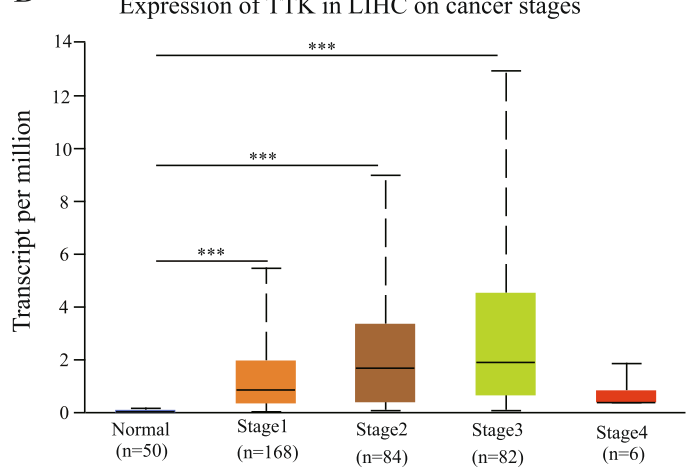

F

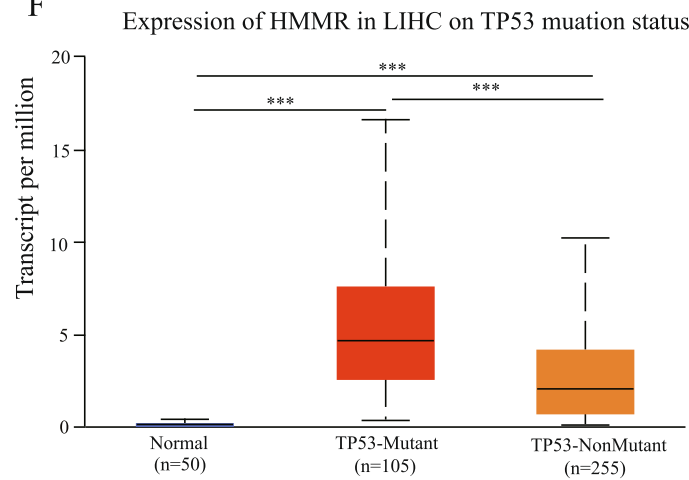

$\mathrm{H}$ Expression of TTK in LIHC on TP53 muation status

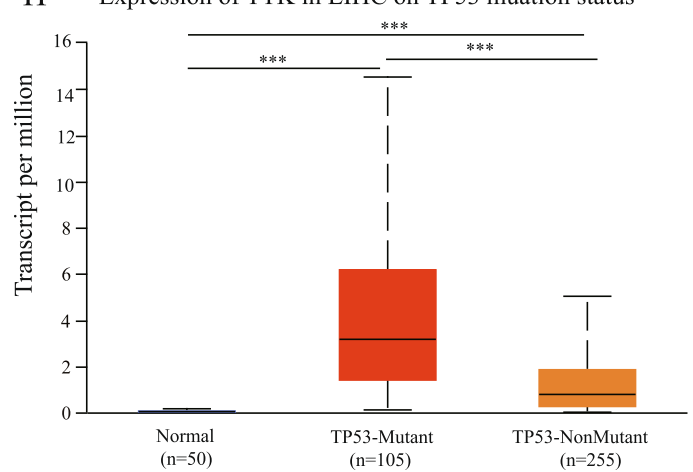

Fig. 4 The mRNA expression levels of prognostic hub gene in liver hepatocellular carcinoma (LIHC) in subgroup analyses. The published online data of gene mRNA expression level were analyzed by UALCAN platform. Subgroup analyses were performed based on patients' LIHC stages (ad) and TP53 mutation status (e-h). T test was performed on the relevant results $\left({ }^{*} P<0.05,{ }^{* *} P<0.01,{ }^{* * *} P<0.001\right)$ 

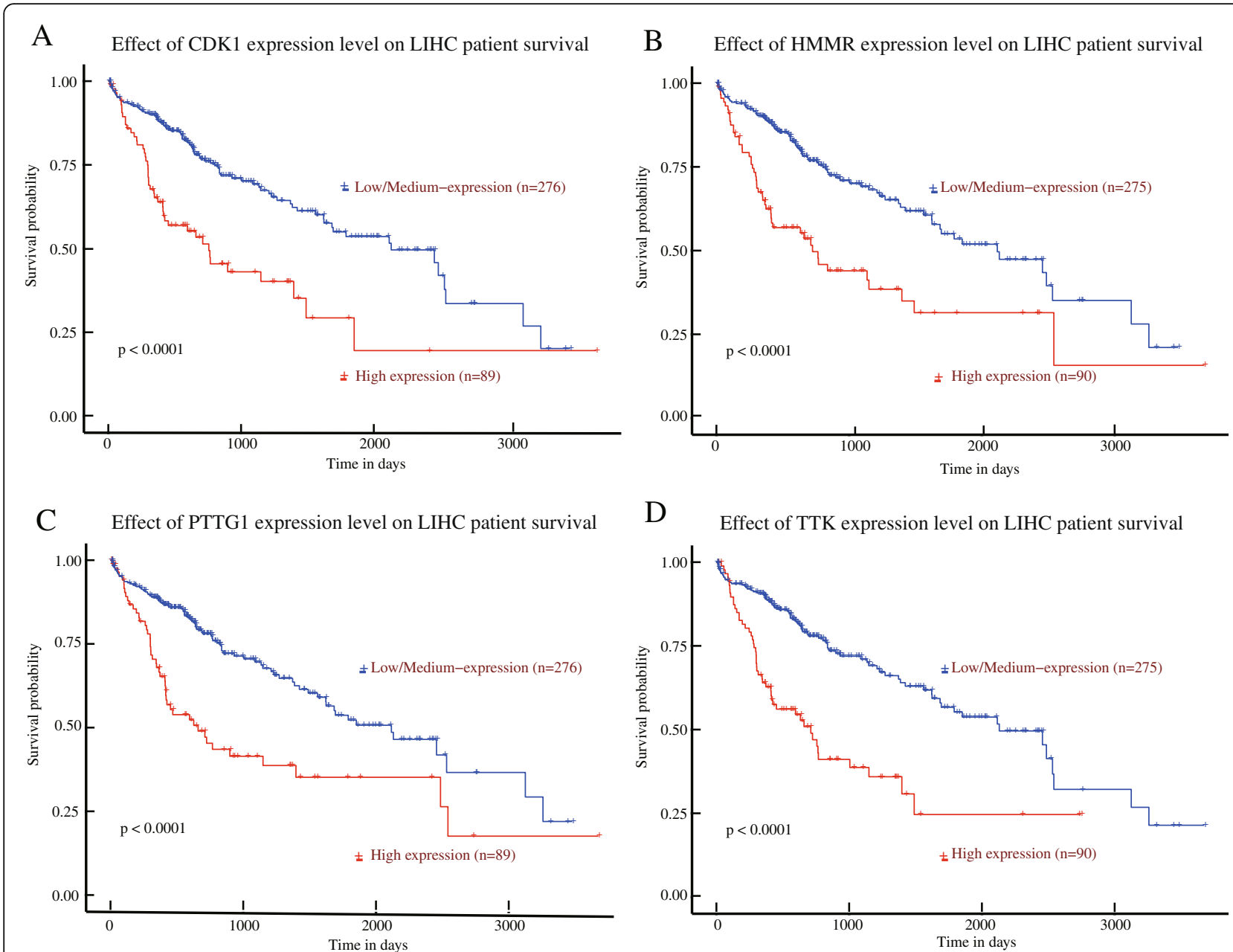

Fig. 5 Overall survival analysis of prognostic hub genes in liver hepatocellular carcinoma (LIHC) was performed by using the UALCAN platform. Survival analysis curve for CDK1 (a), HMMR (b), PTTG1 (c), and TTK (d) in patients with LIHC from The Cancer Genome Atlas (TCGA). Log-rank test was performed on the relevant results

correlation with the infiltrating levels of B cells, macrophages, and neutrophils (Fig. 8d).

The correlation between CDK1, HMMR, PTTG1, and TTK and gene markers for different subsets of immune cells in liver cancer were analyzed through the TIMERrelated modules. As shown in Table 3, the expression levels of CDK1, HMMR, PTTG1, and TTK were significantly associated with most of the immune markers of immune cells, except for natural killer cells.

\section{Immunohistochemical analysis of hub genes in HPA}

Based on the protein expression data from the HPA, the protein expression levels of CDK1, HMMR, PTTG1, and $T T K$ in liver cancer tissues and normal liver tissues were compared by utilizing the antibodiesCAB003799, CAB002433, HPA008890, and CAB013229. The immunohistochemistry results confirmed that the protein expression levels of CDK1, HMMR, PTTG1, and TTK were higher in liver cancer tissues than normal liver tissues (Fig. 9).

\section{Drug-gene interaction analysis of hub genes in DGIdb}

DGIdb was utilized to analyze the drugs that potentially interacted with the four hub genes (CDK1, HMMR, PTTG1, and TTK). Through the DGIdb, 69 drugs interacted with CDK1, HMMR, and TTK, which might help develop new treatment target for liver cancer therapy (Fig. 10).

\section{Discussion}

However, the past 30 years had been characterized by a broadening of understanding of liver cancer's pathogenesis and an advance in diagnostic and therapeutic strategies for managing liver cancer patients, the clinical outcome remained poor [36]. Liver cancer had become a serious global health issue due to the current regimens having limited efficacy in liver 


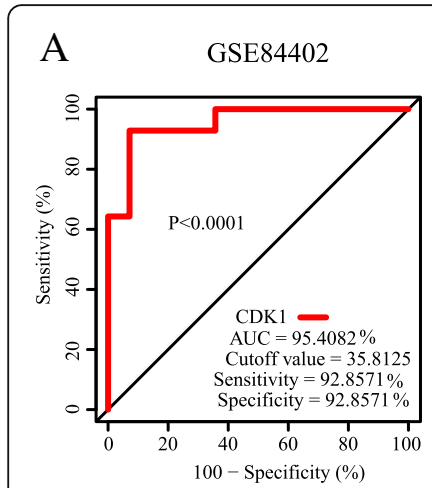

B

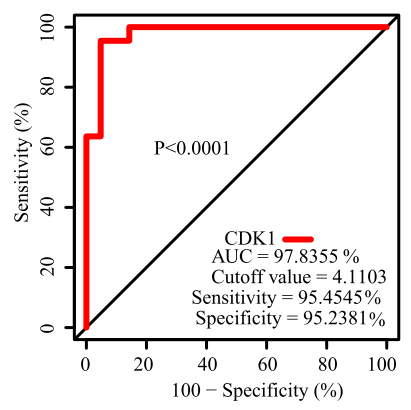

GSE84402

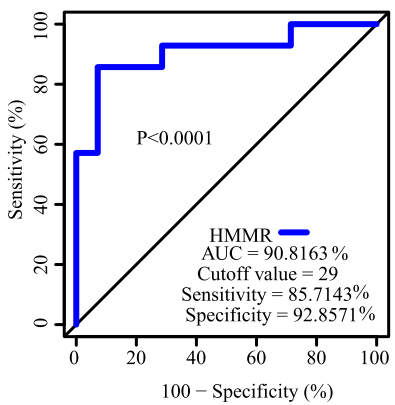

GSE14520

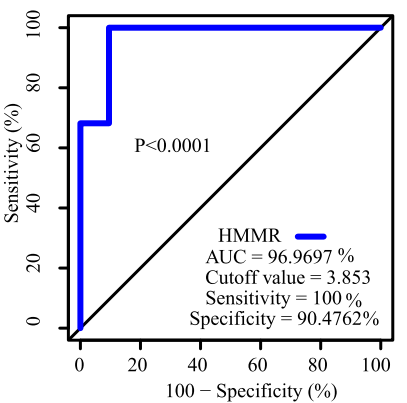

GSE84402

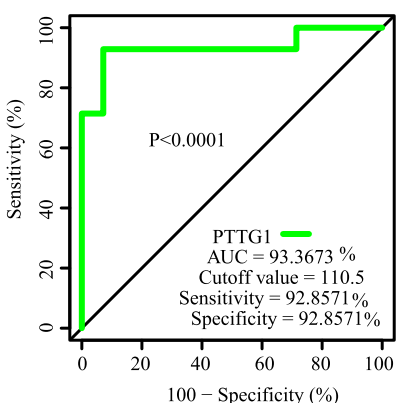

GSE14520

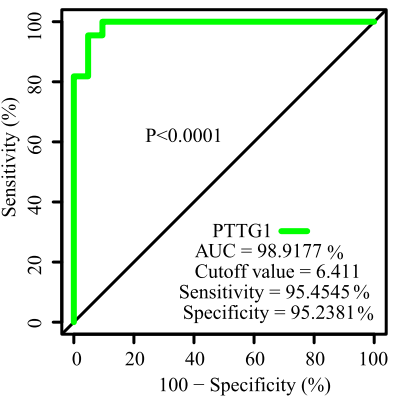

GSE84402

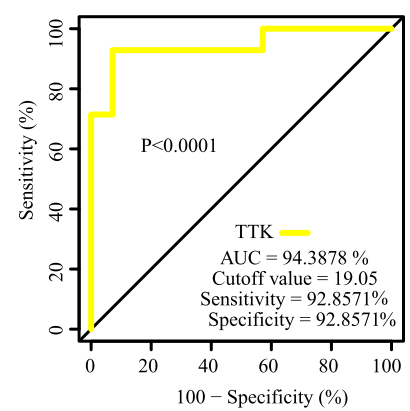

GSE14520

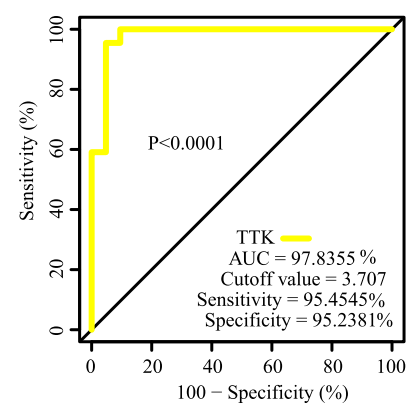

Fig. 6 Receiver operating characteristic (ROC) curves analysis was implemented to evaluate the diagnostic value of four hub genes to distinguish between liver cancer tissues and liver normal tissues. a ROC curves to evaluate the diagnostic efficiency of the CDK1, HMMR, PTTG1, and TTK in internal set (GSE84402) to distinguish between liver cancer tissues and liver normal tissues. $\mathbf{b}$ ROC curves to evaluate the diagnostic efficiency of the CDK1, HMMR, PTTG1, and TTK in external set (GSE14520) to distinguish between liver cancer tissues and liver normal tissues

cancer patients. Meanwhile, searching for specific molecular biomarkers for development and metastasis of liver cancer had important significance in the diagnosis and therapy of liver cancer patients.

In this study, 60 upregulated genes and 108 downregulated genes were identified by bioinformatics method in three expression profiles. The GO and KEGG pathway analysis of DEGs in liver cancer revealed that DEGs were enriched in the function and pathway related to the occurrence and development of liver cancer. Downregulated genes were enriched in the pathway of retinol metabolism, which was associated with the development of liver cancer. The decrease of retinol storage in the liver was observed in hepatocellular carcinoma patients [37]. A recent study revealed that the apoptosis pathway (Bax/Caspase) and cell cycle arrest pathway (P53/P21) could be activated after exposure to the alternating low-intensity and intermediate-frequency electric field in hepatocellular carcinoma spheroids [38]. The study of hepatocellular carcinoma cell lines was similar to our study in that it had shown that hepatocellular carcinoma cells displayed a downregulated metabolic pathway and complement coagulation cascades [39]. Meanwhile, in our study, the role of P450 pathway in the progression of liver cancer was crucial which was similar to the previous studies [40-42]. Interestingly, human T-lymphotropic virus type I (HTLV-1) infection had been identified to be the significant pathway in our study. Previous studies pointed out that HTLV-1 may be associated with the development of the hepatitis $C$ virus infection [43]. As was known to all, the hepatitis $\mathrm{C}$ virus is linked to the development of liver cancer. Emerging studies had found prion disease to be pathological aggregation in malignant tumors related to misfolded p53, a tumor-suppressor protein. The prion-like behavior of oncogenic P53 mutants appeared to be a direct correlation to tumorigenesis [44]. Interestingly, in our study, the downregulated genes were enriched in the pathway of prion disease. The role of prion disease pathway is worthy of further investigation.

In this study, 3 significant TFs were screened from the TF regulatory network, including MAX, MYC, and SREBF1, which played important roles in the formation and development of tumors $[45,46]$. In total, 41 hub genes were extracted out from the DEGs by analyzing the PPI network. The mRNA expression of 4 hub genes, includingCDK1, HMMR, PTTG1, and TTK, were significantly associated with the survival probability of 


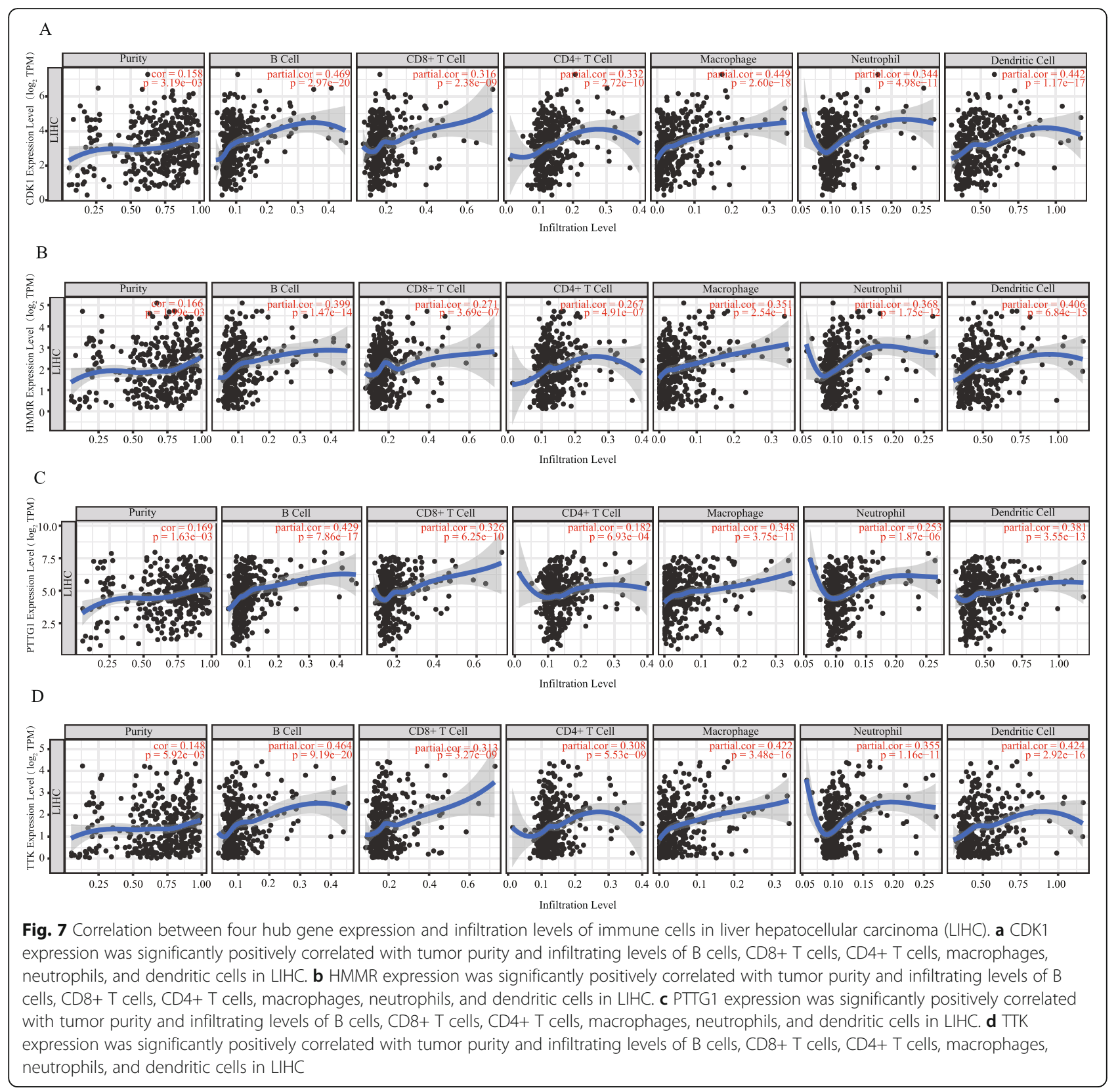

liver cancer patients in TCGA. Moreover, the above 4 hub genes were validated by performing ROC analysis in the external set GSE14520. As a result, these four hub genes showed the excellent diagnostic value for liver cancer, which were consistent with the results of the internal set GSE84402. These results suggested that CDK1, HMMR, PTTG1, and TTK could be the diagnostic biomarkers in liver cancer to distinguish between cancer tissues and normal tissues.

The cyclin-dependent kinase 1 (CDK1), known as cell division control protein 2 , is required for the transition from the $\mathrm{G} 2$ phase into mitosis [47]. The CDK1-cyclinB complex allowed $C D K 1$ to phosphorylate more than one hundred proteins, which promoted nuclear envelope breakdown, chromatin condensation, and spindle assembly [48]. Recent researches had revealed that the expression of $C D K 1$ was high in different types of carcinomas, such as thyroid cancer, pancreatic ductal adenocarcinoma, colorectal cancer, and ovarian cancer and so on [49-52]. The mouse knockout experiments had indicated that $C D K 1$ was essential for mammalian cell proliferation; only $C D K 1$ could initiate the onset of mitosis [53]. Prior research revealed that $C D K 1$ activity was dysregulated by direct genetic alteration in tumorigenesis. Meanwhile, the derangement of P53 pathway or of DNA damage checkpoints indirectly could result in the 


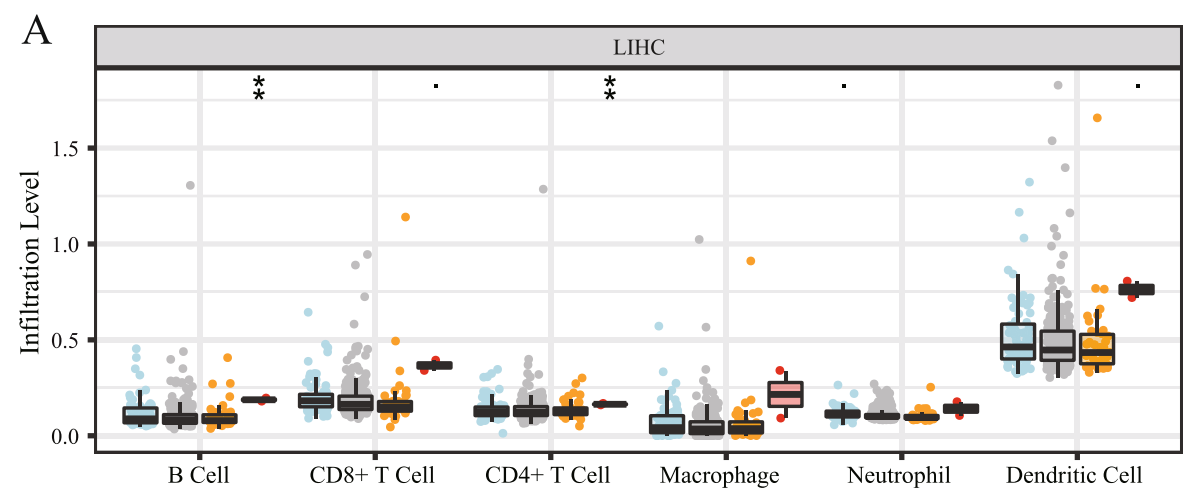

Copy Number

审 Arm-level Deletion

Diploid/Normal

Arm-level Gain

High Amplication

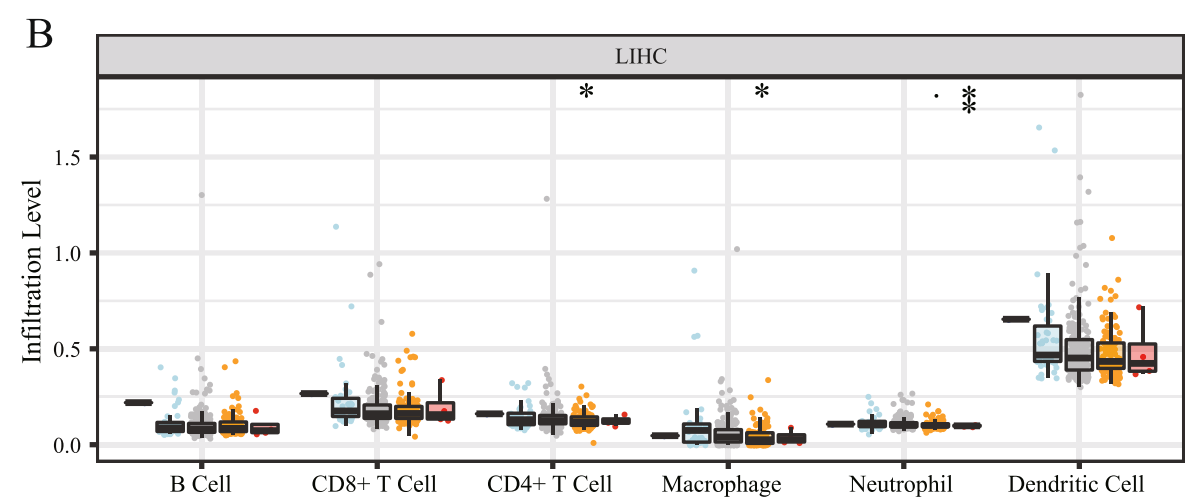

Copy Number

审 Deep Deletion

主 Arm-level Deletion

审 Diploid/Normal

审 Arm-level Gain

官 High Amplication

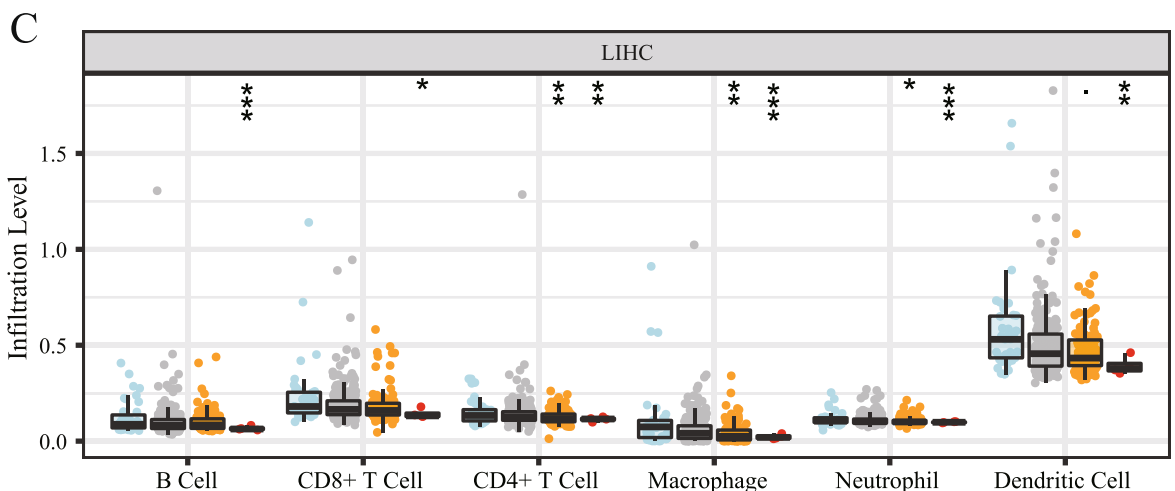

Copy Number

审 Arm-level Deletion

Diploid/Normal

Arm-level Gain

High Amplication

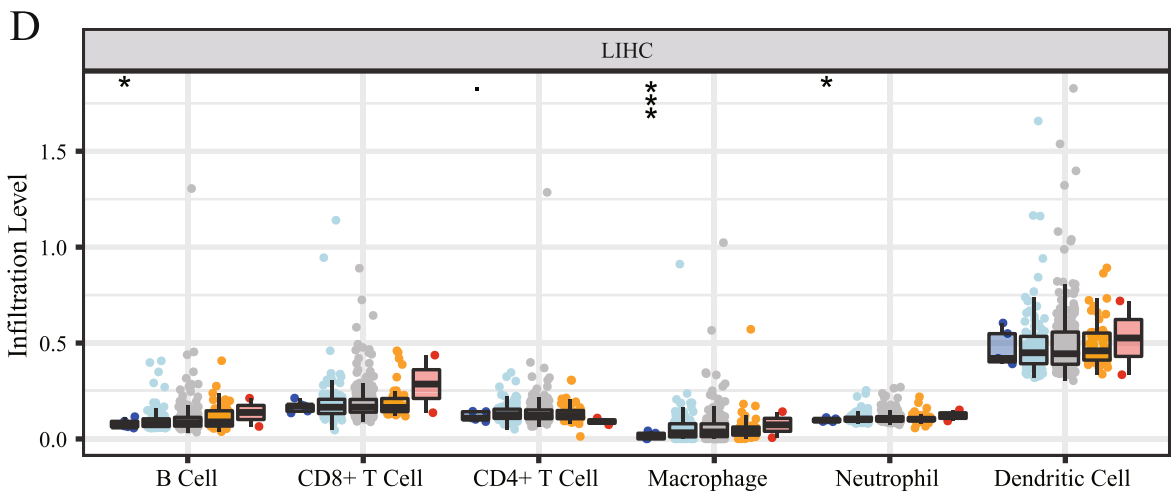

Copy Number

审 Deep Deletion

Arm-level Deletion

审 Diploid/Normal

Arm-level Gain

High Amplication

Fig. 8 (See legend on next page.) 
(See figure on previous page.)

Fig. 8 The association of somatic copy number alterations (SCNA) of four hub genes with immune cell infiltration in liver hepatocellular carcinoma (LIHC). a SCNA of CDK1 with infiltrating levels of B cells, CD8+ T cells, CD4+ T cells, macrophages, neutrophils, and dendritic cells in LIHC. b SCNA of HMMR with infiltrating levels of B cells, CD8+ T cells, CD4+ T cells, macrophages, neutrophils, and dendritic cells in LIHC. c SCNA of PTTG1 with infiltrating levels of B cells, CD8+ T cells, CD4+ T cells, macrophages, neutrophils, and dendritic cells in LIHC. d SCNA of TTK with infiltrating levels of B cells, CD8+ T cells, CD4+ T cells, macrophages, neutrophils, and dendritic cells in LIHC. SCNA of hub genes were divided into five levels, including deep deletion, arm-level deletion, normal, arm-level gain, and high amplification

deregulation of $C D K 1$ [54, 55]. As the previous study identified, $C D K 1$ was overexpressed in hepatocellular carcinoma and was related to the development of tumor through the CDK1/PDK1/ $\beta$-Catenin pathway, which could predict worse survival outcomes $[56,57]$.

In our study, the mRNA expression levels and protein levels of $C D K 1$ were higher in liver cancer samples than normal liver samples; meanwhile, the mRNA expression levels of CDK1 were associated with advanced cancer stages and TP53 mutation. Liver hepatocellular carcinoma patients with high expression levels of CDK1 were associated with lower overall survival rates. These results indicated that $C D K 1$ was a prognostic biomarker in liver cancer. CDK1 SCNA was closely relevant to immune cell infiltration level, and further analysis revealed that CDK1 expression was positively correlated with the infiltration levels of B cells, CD8 $+\mathrm{T}$ cells, CD4+ T cells, macrophages, neutrophils, and dendritic cells. The correlation between $C D K 1$ expression and immune cell gene markers revealed that $C D K 1$ regulates liver cancer tumor immunity through multiple immune cell populations. Our results suggested that high expression levels of $C D K 1$ could increase immune activation and cytotoxicity of the immune system in liver cancer by increasing the infiltration of immune cells. We inferred that CDK1 might be involved in the occurrence and development of liver cancer by regulating the P53 pathway and immune system. Due to the lack of evidence on the immunologic mechanism of CDK1, the immunologic mechanism of $C D K 1$ is worthy of further testing.

The hyaluronan-mediated motility receptor (HMMR) is identified as a hyaluronan receptor purified from the supernatants of murine cells [58]. The prior study had shown that the $H M M R$ was crucial for the spindle to align correctly; even the few mice without $H M M R$ were able to survive or many suffered from deformed and underdeveloped brains [59-61]. In our study, the biological process results had shown that the HMMR was enriched in transition of mitotic cell cycle. Extensive research had identified that the HMMR was overexpressed in non-small cell lung cancer, stomach cancer, bladder cancer, etc. [62-64]. The expression levels of the HMMR might be a specific prognostic marker in terms of progressions-free survival in papillary muscle-invasive bladder cancer [65]. The $H M M R$, which was as the downstream gene upregulated by testis-specific protein Y-encoded demonstrated that it could be involved in the initiation and development of hepatocellular carcinoma via the activation of $H A-H M M R$ signaling cascade [66].

Our results had shown that the expression of $H M M R$ was higher in hepatocellular carcinoma tissues than normal liver tissues on mRNA levels and protein levels, and high expression of $H M M R$ in liver hepatocellular carcinoma patients was an adverse prognostic factor. The genetic alteration of $H M M R$ in liver cancer such as armlevel gain and high amplification could be found in our results, and further analysis indicated that high expression of $H M M R$ could predict the elevated infiltration levels of B cells, CD8+ T cells, CD4+ T cells, macrophages, neutrophils, and dendritic cells. We inferred that $H M M R$ could affect the activation and polarization of macrophages, especially for the M2 subtype. M2 macrophages were regarded as "renegade" immune cells which contributed to poor prognosis in liver hepatocellular carcinoma and promote cancer invasiveness [67]. In our study, HMMR was found to be positively correlated with M2 gene markers (CD163, VSIG4, and MS4A4A). These results suggested that $H M M R$ might induce macrophage-related immune response by activating M2 subsets. The mechanism of $H M M R$ in liver cancer is worthy of further testing.

The pituitary tumor transforming gene-1 (PTTG1) is a ubiquitously expressed regulator of sister-chromatid separation, and it also acts as the transcription factor [68]. In different types of cancer, including gastrointestinal tumors, urological tumors, and gynecologic tumors, the upregulation of PTTG1 was related to unfavorable tumor phenotype and adverse prognosis [69-73]. The prior study had shown that the expression of the PTTG1 in HepG2 and SMMC-7721 cells were higher than L02 cells. SiRNA knockdown of PTTG1 induced the transformation in expression of P21 and P53 in HepG2 and SMMC-7721 cells [74]. Interestingly, in our study, the PTTG1 was not enriched in the pathway of P53. The mechanism of PTTG1 in liver cancer is worthy of an indepth study.

Fujii et al. [75] reported that the PTTG1 was obviously overexpressed in hepatocellular carcinoma, which was consistent with our results that the mRNA expression levels and protein levels of PTTG1 were higher in liver 
Table 3 Correlation analysis between CDK1, HMMR, PTTG1, and TTK and related immune markers in immune cells, as evaluated using TIMER

\begin{tabular}{|c|c|c|c|c|c|c|c|c|c|}
\hline \multirow[t]{2}{*}{ Description } & \multirow{2}{*}{$\begin{array}{l}\text { Gene } \\
\text { marker }\end{array}$} & \multicolumn{2}{|l|}{ CDK1 } & \multicolumn{2}{|l|}{ HMMR } & \multicolumn{2}{|l|}{ PTTG1 } & \multicolumn{2}{|l|}{ TTK } \\
\hline & & Cor & $P$ & Cor & $\mathbf{P}$ & Cor & $\mathbf{P}$ & Cor & $\mathbf{P}$ \\
\hline \multirow[t]{2}{*}{ CD8+ T cell } & CD8A & 0.198 & $* * *$ & 0.139 & ** & 0.164 & ** & 0.188 & *** \\
\hline & CD8B & 0.184 & $* * *$ & 0.096 & 0.064 & 0.226 & $* * *$ & 0.165 & $* *$ \\
\hline \multirow[t]{3}{*}{ T cell (general) } & CD3D & 0.274 & $* * *$ & 0.154 & $* *$ & 0.333 & *** & 0.266 & *** \\
\hline & CD3E & 0.202 & $* * *$ & 0.120 & * & 0.175 & *** & 0.195 & *** \\
\hline & CD2 & 0.216 & $* * *$ & 0.121 & * & 0.204 & *** & 0.204 & *** \\
\hline \multirow[t]{2}{*}{ B cell } & CD19 & 0.273 & $* * *$ & 0.204 & $* * *$ & 0.247 & *** & 0.273 & *** \\
\hline & CD79A & 0.158 & $* *$ & 0.065 & 0.212 & 0.116 & * & 0.177 & *** \\
\hline \multirow[t]{2}{*}{ Monocyte } & CD86 & 0.284 & $* * *$ & 0.266 & $* * *$ & 0.250 & *** & 0.283 & *** \\
\hline & CD115 & 0.131 & * & 0.138 & $* *$ & 0.102 & * & 0.119 & * \\
\hline \multirow[t]{3}{*}{ TAM } & CCL2 & 0.039 & 0.459 & 0.023 & 0.656 & -0.023 & 0.665 & 0.021 & 0.682 \\
\hline & CD68 & 0.230 & $* * *$ & 0.186 & $* * *$ & 0.149 & * & 0.204 & *** \\
\hline & IL10 & 0.219 & $* * *$ & 0.223 & $* * *$ & 0.156 & * & 0.235 & *** \\
\hline \multirow[t]{3}{*}{ M1 macrophage } & NOS2 & -0.020 & 0.695 & 0.080 & 0.123 & -0.140 & $* *$ & -0.005 & 0.926 \\
\hline & IRF5 & 0.394 & $* * *$ & 0.407 & $* * *$ & 0.291 & *** & 0.373 & *** \\
\hline & $\operatorname{cox} 2$ & 0.101 & 0.053 & 0.071 & 0.171 & -0.025 & 0.637 & 0.094 & 0.070 \\
\hline \multirow[t]{3}{*}{ M2 Macrophage } & CD163 & 0.067 & 0.197 & 0.153 & $* *$ & -0.022 & 0.676 & 0.073 & 0.160 \\
\hline & VSIG4 & 0.080 & 0.123 & 0.138 & $* *$ & 0.024 & 0.647 & 0.059 & 0.255 \\
\hline & MS4A4A & 0.089 & 0.086 & 0.142 & $* *$ & 0.027 & 0.601 & 0.079 & 0.128 \\
\hline \multirow[t]{3}{*}{ Neutrophils } & CD66b & 0.123 & * & 0.096 & 0.066 & 0.094 & 0.071 & 0.107 & * \\
\hline & CD11b & 0.257 & $* * *$ & 0.333 & $* * *$ & 0.237 & *** & 0.280 & *** \\
\hline & CCR7 & 0.089 & 0.086 & 0.045 & 0.385 & -0.030 & 0.569 & 0.070 & 0.181 \\
\hline \multirow[t]{3}{*}{ Natural killer cell } & KIR3DL1 & 0.010 & 0.843 & 0.068 & 0.189 & -0.053 & 0.308 & 0.009 & 0.869 \\
\hline & KIR2DL1 & -0.035 & 0.500 & -0.023 & 0.656 & -0.068 & 0.190 & -0.044 & 0.393 \\
\hline & KIR2DS4 & 0.075 & 0.148 & 0.076 & 0.142 & 0.029 & 0.581 & 0.044 & 0.400 \\
\hline \multirow[t]{3}{*}{ Dendritic cell } & CD11C & 0.331 & $* * *$ & 0.310 & $* * *$ & 0.246 & *** & 0.326 & *** \\
\hline & CD1C & 0.121 & * & 0.066 & 0.204 & 0.041 & 0.434 & 0.104 & * \\
\hline & NRP1 & 0.231 & $* * *$ & 0.195 & $* * *$ & 0.005 & 0.916 & 0.180 & *** \\
\hline PDL1 & CD274 & 0.209 & $* * *$ & 0.334 & $* * *$ & 0.062 & 0.230 & 0.062 & 0.230 \\
\hline \multirow[t]{5}{*}{ Th I } & STAT4 & 0.262 & $* * *$ & 0.179 & $* * *$ & 0.215 & *** & 0.246 & *** \\
\hline & STAT1 & 0.372 & $* * *$ & 0.372 & $* * *$ & 0.248 & *** & 0.398 & *** \\
\hline & TBX21 & 0.081 & 0.119 & 0.050 & 0.341 & 0.018 & 0.736 & 0.084 & 0.107 \\
\hline & CD4 & 0.222 & $* * *$ & 0.232 & $* * *$ & 0.123 & * & 0.228 & *** \\
\hline & IFNG & 0.266 & $* * *$ & 0.219 & $* * *$ & 0.285 & *** & 0.275 & *** \\
\hline \multirow[t]{4}{*}{ Th 2} & GATA3 & 0.203 & $* * *$ & 0.135 & $* *$ & 0.133 & * & 0.185 & *** \\
\hline & STAT6 & 0.114 & * & 0.192 & $* * *$ & -0.108 & * & 0.115 & * \\
\hline & CXCR4 & 0.315 & $* * *$ & 0.224 & $* * *$ & 0.204 & *** & 0.292 & *** \\
\hline & CCR4 & 0.206 & $* * *$ & 0.220 & $* * *$ & -0.023 & 0.663 & 0.213 & *** \\
\hline \multirow[t]{4}{*}{ Treg } & FOXP3 & 0.163 & $* *$ & 0.271 & $* * *$ & 0.023 & 0.655 & 0.205 & *** \\
\hline & CCR8 & 0.392 & $* * *$ & 0.418 & $* * *$ & 0.209 & *** & 0.403 & *** \\
\hline & STAT5B & 0.247 & $* * *$ & 0.355 & $* * *$ & -0.022 & 0.676 & 0.278 & *** \\
\hline & TGFB1 & 0.278 & $* * *$ & 0.174 & $* * *$ & 0.207 & *** & 0.253 & *** \\
\hline \multirow[t]{5}{*}{ T cell exhaustion } & PD-1 & 0.330 & $* * *$ & 0.196 & $* * *$ & 0.333 & $* * *$ & 0.308 & $* * *$ \\
\hline & CTLA4 & 0.357 & $* * *$ & 0.244 & $* * *$ & 0.384 & *** & 0.348 & *** \\
\hline & LAG3 & 0.294 & $* * *$ & 0.205 & $* * *$ & 0.348 & *** & 0.318 & $* * *$ \\
\hline & TIM-3 & 0.296 & $* * *$ & 0.281 & $* * *$ & 0.272 & $* * *$ & 0.289 & $* * *$ \\
\hline & GZMB & 0.092 & 0.078 & 0.048 & 0.355 & 0.123 & * & 0.065 & 0.212 \\
\hline
\end{tabular}


A

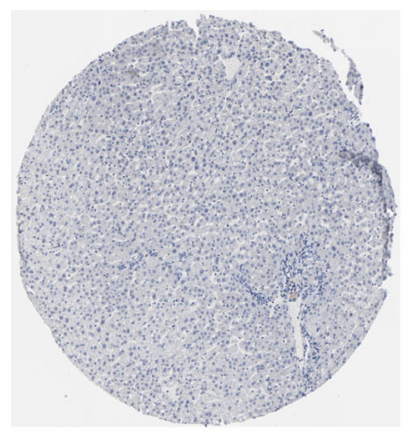

B

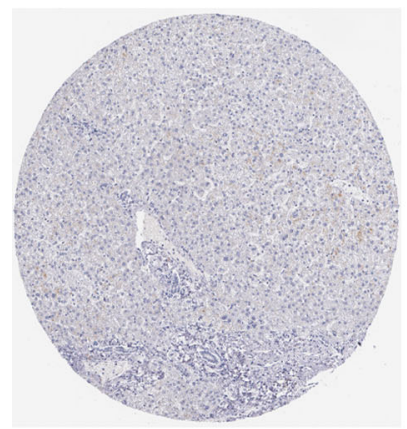

C

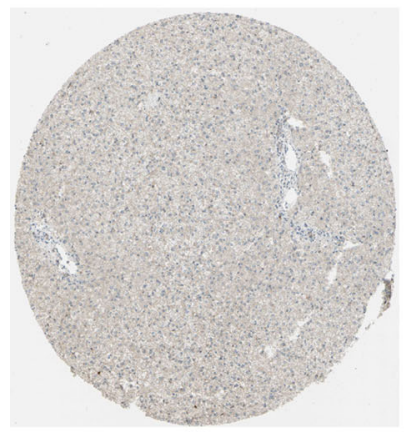

D

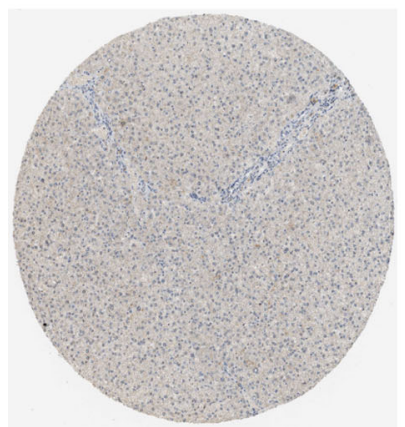

Normal liver tissue

CAB003799

Male, age 72

Staining: Not Detected

Intensity: Negative

Quantity: None

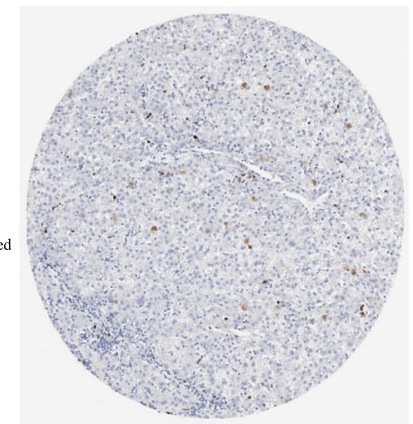

Liver hepatocellular carcinoma

CAB003799

Male, age 72

Staining: Medium

Intensity: Strong

Quantity: $<25 \%$
Normal liver tissue

CAB002433

Female, age 32

Staining: Not Detected

Intensity: Negative

Quantity: None

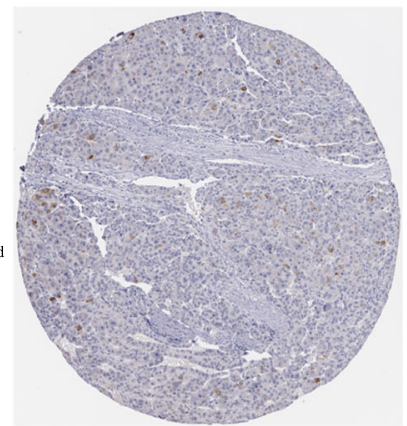

Liver hepatocellular carcinom

CAB002433

Male, age 76

Staining: Low

Intensity: Moderate

Quantity: $<25 \%$

Liver hepatocellular carcinoma

HPA008890

Female, age 58

Staining: Low

Intensity: Weak

DQuantity: $75 \%-25 \%$

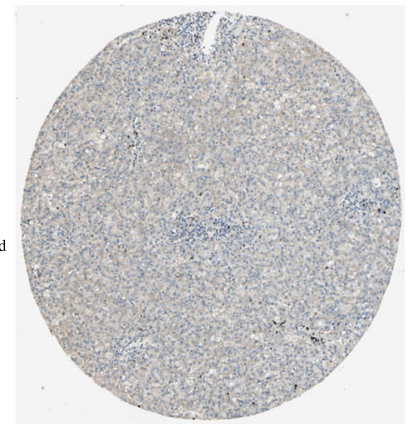

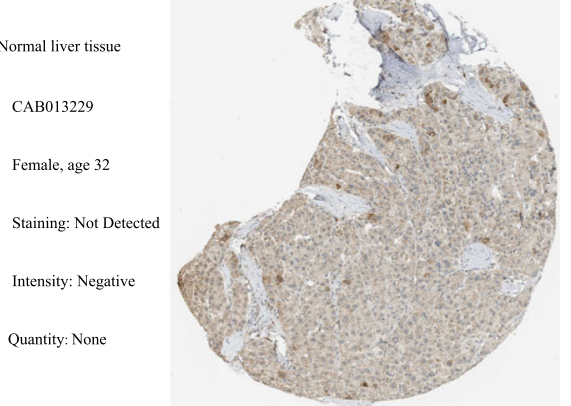

Liver hepatocellular carcinoma

HPA008890

Male, age 80

Staining: Medium

Intensity: Strong

Quantity: $<25 \%$

Fig. 9 (See legend on next page.) 
(See figure on previous page.)

Fig. 9 Immunohistochemistry (IHC) of four hub genes based on the Human Protein Atlas (HPA). a Protein levels of CDK1 in normal liver tissue and liver hepatocellular carcinoma tissue. b Protein levels of HMMR in normal liver tissue and liver hepatocellular carcinoma tissue. c Protein levels of PTTG1 in normal liver tissue and liver hepatocellular carcinoma tissue. $\mathbf{d}$ Protein levels of TTK in normal liver tissue and liver hepatocellular carcinoma tissue

cancer tissues than normal liver tissues. The high expression of PTTG1 was an adverse factor in survival rates of liver hepatocellular carcinoma patients. PTTG1 SCNA was closely relevant to immune cell infiltration level, including arm-level gain and high amplification. PTTG1 expression was positively associated with immune cells. The prior research identified that PTTG1 was upregulated in $\mathrm{T}$ cell proliferation [76], and this was consistent with our results. We hypothesized that PTTG1 was closely related to the immune response, and the mechanism of PTTG1 in liver cancer is needed to be further explored.

The threonine tyrosine kinase (TTK) gene is located on chromosome 6q13-q21 and encodes a serine/threonine and tyrosine protein kinase. The TTK is an important component of the spindle of assembly checkpoint that ensures the fidelity of chromosome segregation [77]. The previous study had shown that elevated of TTK could cause centrosome enlargement and chromosomal instability, leading to tumorigenesis [78]. The TTK could be hardly detected in normal tissues, via Northern blot, except the testis and placenta [79].
However, high expression levels of TTK could be detected in different types of cancer, including glioblastoma, esophageal cancer, and breast cancer [80-82]. The prostate cancer patients with high expression levels of TTK had a shorter time to relapse [83]. The prior research suggested the TTK could regulate the TGF- $\beta$ signaling pathway [84]. The new research had speculated that TTK could regulate the proliferation and apoptosis of cancer cells via Akt-mTOR signaling pathway [85]. Liu et al [86] reported that TTK was overexpressed in $77.63 \%$ (118/152) hepatocellular carcinoma specimens.

In our study, the TTK was overexpressed in liver hepatocellular carcinoma tissues on mRNA and protein levels; liver hepatocellular carcinoma patients with high expression levels of TTK had lower survival rates. The TTK SCNA was focused on deep deletion. TTK expression was positively correlated with the infiltration levels of $\mathrm{B}$ cells, CD8+ T cells, CD4+ T cells, macrophages, neutrophils, and dendritic cells. A prior study indicated that TTK mutations presented the strongest association with elevated PD-L1 expression [87]. Interestingly, in our study, the TTK did not present a strong association

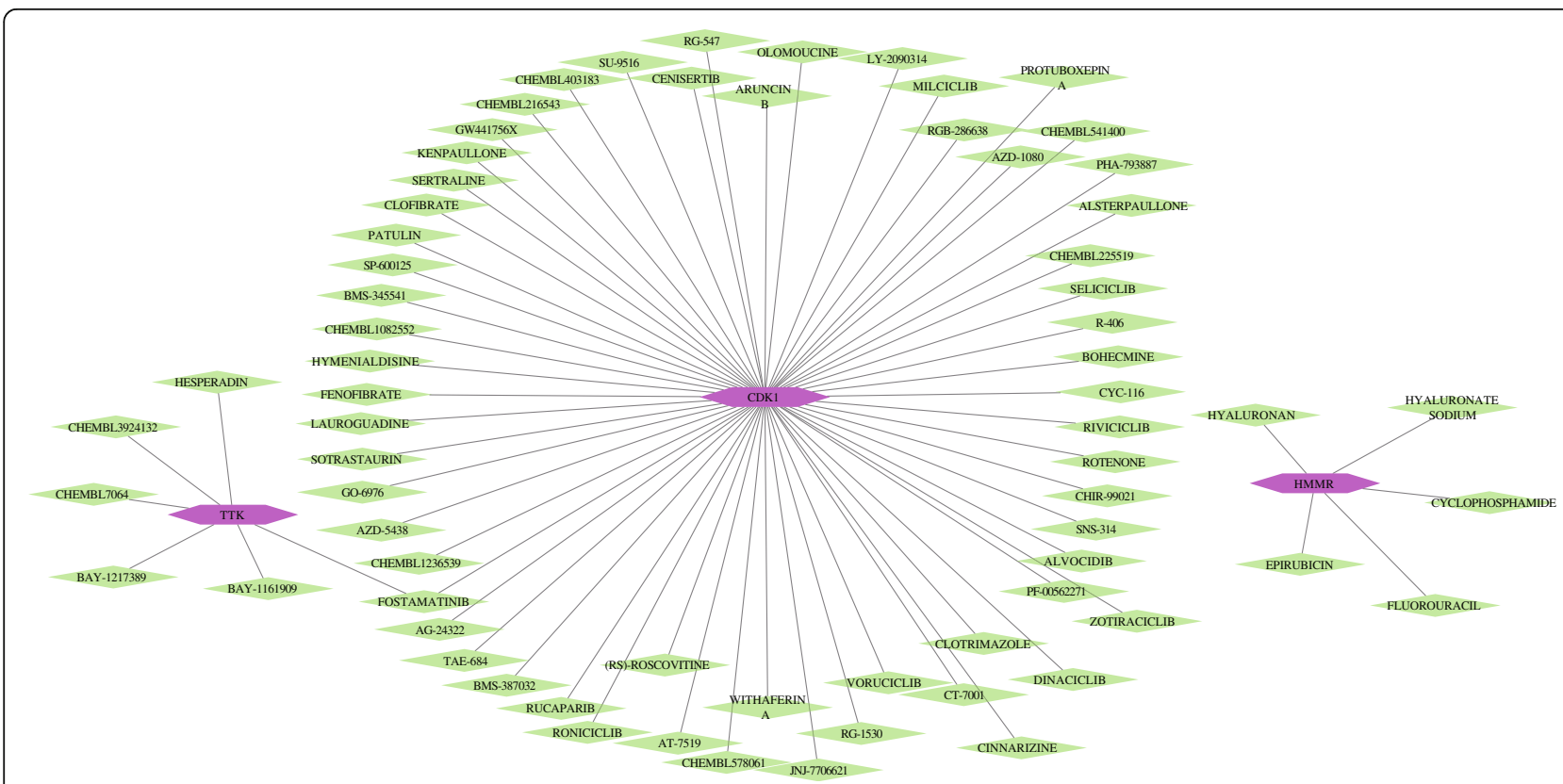

Fig. 10 Drug-hub gene interaction network. The drug-hub gene interaction network contained 72 nodes and 70 sides. Purple nodes represented hub genes. Green nodes represented the drug. The line represented interaction relationship between the hub genes and the drug 
with the PD-L1. Nonetheless, understanding the exact role of TTK in PD-L1 regulation is required to further test.

The fostamatinib was the spleen tyrosine kinase (SYK) inhibitor, and it was able to inhibit both parental and sorafenib-resistant (SR) HCC cell lines in vitro and xenograft models [88]. In our study, the fostamatinib interacted with the $C D K 1$ and TTK, suggesting that CDK1 and TTK might be potential drug targets for fostamatinib in anti-HCC therapy. The new study suggested that the inhibition of cyclin E1 by the cyclin-dependent kinase inhibitors dinaciclib and alvocidib (flavopiridol) could suppress HCC cell growth by inducing apoptosis and enhance the killing function of regorafenib and sorafenib in vitro and vivo [89]. In our results, the dinaciclib and alvocidib interacted with the CDK1. The rucaparib (AG014699), which was the inhibitor of the poly (ADP-ribose) polymerase-1 (PARP-1), might induce the apoptosis of HepG2 cells through the mitochondrial pathway and induced the migration of HepG2 cells by upregulating the PTEN and increasing the TIMP-3/ MMP-3 ratio [90]. The traditional chemotherapeutic drugs (epirubicin, cyclophosphmide, and fluorouracil) played the important roles in treatment of liver cancer [91]. In our study, the $H M M R$ had relationship with the epirubicin, cyclophosphmide, and fluorouracil. The pharmacological mechanisms between the hub genes and drugs are needed to be further explored.

The main restriction of our study was only at the level of bioinformatics analysis. So it was in urgent need of cytological experiments, animal experiments, and drug trials, etc., to identify these hub genes in liver cancer.

\section{Conclusions}

To conclude, 168 DEGs was identified in liver cancer by integrated analysis in our study, which contained $41 \mathrm{hub}$ genes. Four of these hub genes, including CDK1, HMMR, PTTG1, and TTK, were filtered out as potential biomarkers for diagnosis and prognosis of liver cancer. The expressions of CDK1, HMMR, PTTG1, and TTK were closely related to the immune cell infiltration and signaling pathway activation. Meanwhile, the CDK1, $H M M R$, and TTK had close interaction with new types of anticancer agents and traditional chemotherapy drugs. Therefore, laboratory and clinical research are needed to identify our results associated with pathogenesis of liver cancer, which can offer the last and accurate information for the prevention and therapy of liver cancer.

\section{Acknowledgements}

We would like to thank Ting Luo (Jinan University Guangzhou) for the help in reviewing and editing this paper. Lei Li (Guangdong University of Technology) edited the English language of the final manuscript. LiangYaLun (The First Affiliated Hospital of Jinan University, Guangzhou) edited the English grammar of the revised manuscript.

\section{Authors' contributions}

$\mathrm{XL}$ performed the study and wrote the manuscript. CW and ZD conceived and designed the study. $M Z, B G$, and QC revised and edited the manuscript. All authors read and approved this manuscript. All authors agreed to take responsibility and be accountable for the contents of the article and to share responsibility to answer any questions raised about the accuracy or integrity of the published work.

\section{Funding}

This research received no specific grant from any funding agency in the public, commercial, or not-for-profit sectors. The authors declare that they have no conflict of interest.

\section{Availability of data and materials}

The datasets used and analyzed in the study are available from the corresponding author on reasonable request. The datasets analyzed in the study could be found in the GEO portal (https://www.ncbi.nlm.gov/geo) and TCGA portal (https://portal.gdc.cancer.gov/).

\section{Declarations}

Ethics approval and consent to participate

The study is the bioinformatics analysis article. The data in our study were obtained from the free online databases and the ethical approval was not necessary. There are no animal and human experiments involved in the study. There are no human subjects in the article and informed consent was not necessary.

\section{Consent for publication}

Not applicable.

\section{Competing interests}

The author(s) declared no potential conflicts of interest with respect to the research, authorship, and/or publication of this article.

\section{Author details}

'Department of Gastrointestinal Surgery, the First Affiliated Hospital of Jinan University, No.613 Huangpu Road West, Guangzhou 510630, China. ${ }^{2}$ Department of Respiratory, the First Affiliated Hospital of Jinan University, Guangzhou 510630, China. ${ }^{3}$ Department of Oncology, the First Affiliated Hospital of Jinan University, Guangzhou 510630, China.

Received: 26 January 2021 Accepted: 16 June 2021

Published online: 29 June 2021

\section{References}

1. Zheng R, Qu C, Zhang S, Zeng H, Sun K, Gu X, et al. Liver cancer incidence and mortality in China: temporal trends and projections to 2030. Chin J Cancer Res. 2018;30(6):571-9. https://doi.org/10.21147/j. issn.1000-9604.2018.06.01.

2. Sia D, Villanueva A, Friedman SL, Llovet JM. Liver cancer cell of origin, molecular class, and effects on patient prognosis. Gastroenterology. 2017; 152(4):745-61. https://doi.org/10.1053/j.gastro.2016.11.048.

3. Bray F, Ferlay J, Soerjomataram I, Siegel RL, Torre LA, Jemal A. Global cancer statistics 2018: GLOBOCAN estimates of incidence and mortality worldwide for 36 cancers in 185 countries. CA Cancer J Clin. 2018;68(6):394-424. https://doi.org/10.3322/caac.21492.

4. de Martel C, Maucort-Boulch D, Plummer M, Franceschi S. World-wide relative contribution of hepatitis $B$ and $C$ viruses in hepatocellular carcinoma. Hepatology. 2015;62(4):1190-200. https://doi.org/10.1002/ hep.27969.

5. Massarweh NN, El-Serag HB. Epidemiology of hepatocellular carcinoma and intrahepatic cholangiocarcinoma. Cancer Control. 2017;24: 1073274817729245.

6. Poon D, Anderson $\mathrm{BO}$, Chen LT, et al. Management of hepatocellular carcinoma in Asia: consensus statement from the Asian Oncology Summit 2009. LancetOncol. 2009;10:1111-8.

7. Nakano S, Eso Y, Okada H, Takai A, Takahashi K, Seno H. Recent advances in immunotherapy for hepatocellular carcinoma. Cancers. 2020;12(4):775. https://doi.org/10.3390/cancers12040775. 
8. BBamodu OA, Chang HL, Ong JR, et al. Elevated PDK1 expression drives PI3K/AKT/MTOR signaling promotes radiation-resistant and dedifferentiated phenotype of hepatocellular carcinoma. Cells. 2020;9(3):746. https://doi. org/10.3390/cells9030746.

9. Zhang Z, Chen P, Xie H, Cao P. Using circulating tumor DNA as a novel biomarker to screen and diagnose hepatocellular carcinoma: a systematic review and meta-analysis. Cancer Med. 2020;9(4):1349-64. https://doi.org/1 $0.1002 /$ cam4.2799.

10. Mou SJ, Yang PF, Liu YP, Xu N, Jiang WW, Yue WJ. BCLAF1 promotes cell proliferation, invasion and drug-resistance though targeting IncRNA NEAT1 in hepatocellular carcinoma. Life Sci. 2020;242:117177. https://doi.org/10.101 6/j.lfs.2019.117177.

11. Lu Z, Yu Y, Ding X, Jin D, Wang G, Zhou Y, et al. LncRNA FLJ33360 accelerates the metastasis in hepatocellular carcinoma by targeting miRNA140/MMP9 axis. Am J Transl Res. 2020;12(2):583-91.

12. Liu C, Zhang M, Zhao J, Zhu X, Zhu L, Yan M, et al. LncRNA FOXD3-AS1 mediates AKT pathway to promote growth and invasion in hepatocellular carcinoma through regulating RICTOR. Cancer Biother Radiopharm. 2020; 35(4):292-300. https://doi.org/10.1089/cbr.2019.3335.

13. Gao J, Dai C, Yu X, Yin XB, Zhou F. LncRNA LEF1-AS1 silencing diminishes EZH2 expression to delay hepatocellular carcinoma development by impairing CEBPB-interaction with CDCA7. Cell Cycle. 2020;19(8):870-83. https://doi.org/10.1080/15384101.2020.1731052.

14. Wang $H$, Huo X, Yang XR, et al. STAT3-mediated upregulation of IncRNA HOXD-AS1 as a ceRNA facilitates liver cancer metastasis by regulating SOX4. Mol Cancer. 2017;16:36.

15. Shimada S, Mogushi K, Akiyama Y, Furuyama T, Watanabe S, Ogura T, et al. Comprehensive molecular and immunological characterization of hepatocellular carcinoma. EBioMedicine. 2019;40:457-70. https://doi.org/10.1 016/j.ebiom.2018.12.058

16. Huang da W, Sherman BT, Lempicki RA. Systematic and integrative analysis of large gene lists using DAVID bioinformatics resources. Nat Protoc. 2009;4:44-57.

17. Huang da W, Sherman BT, Lempicki RA. Bioinformatics enrichment tools: paths toward the comprehensive functional analysis of large gene lists. Nucleic Acids Res. 2009;37:1-13.

18. Szklarczyk D, Morris JH, Cook H, Kuhn M, Wyder S, Simonovic M, et al. The STRING database in 2017: quality-controlled protein-protein association networks, made broadly accessible. Nucleic Acids Res. 2017;45(D1):D362-8. https://doi.org/10.1093/nar/gkw937.

19. Bader GD, Hogue $C W$. An automated method for finding molecular complexes in large protein interaction networks. BMC Bioinformatics. 2003; 4(1):2. https://doi.org/10.1186/1471-2105-4-2.

20. Matys V, Fricke E, Geffers R, Gössling E, Haubrock M, Hehl R, et al. TRANSFAC : transcriptional regulation, from patterns to profiles. Nucleic Acids Res. 2003;31(1):374-8. https://doi.org/10.1093/nar/gkg108.

21. Matys V, Kel-Margoulis OV, Fricke E, Liebich I, Land S, Barre-Dirrie A, et al. TRANSFAC and its module TRANSCompel: transcriptional gene regulation in eukaryotes. Nucleic Acids Res. 2006;34(90001):D108-10. https://doi.org/10.1 093/nar/gkj143.

22. Rouillard AD, Gundersen GW, Fernandez NF, et al. The Harmonizome: a collection of processed datasets gathered to serve and mine knowledge about genes and proteins. Database (Oxford). 2016;2016:baw100. https://doi. org/10.1093/database/baw100.

23. Chandrashekar DS, Bashel B, Balasubramanya SAH, Creighton CJ, PonceRodriguez I, Chakravarthi BVSK, et al. UALCAN: a portal for facilitating tumor subgroup gene expression and survival analyses. Neoplasia. 2017;19(8):64958. https://doi.org/10.1016/j.neo.2017.05.002.

24. Roessler S, Jia HL, Budhu A, Forgues $\mathrm{M}$, Ye QH, Lee JS, et al. A unique metastasis gene signature enables prediction of tumor relapse in earlystage hepatocellular carcinoma patients. Cancer Res. 2010;70(24):10202-12 https://doi.org/10.1158/0008-5472.CAN-10-2607.

25. Roessler S, Long EL, Budhu A, Chen Y, Zhao X, Ji J, et al. Integrative genomic identification of genes on $8 p$ associated with hepatocellular carcinoma progression and patient survival. Gastroenterology. 2012;142(4): 957-66. https://doi.org/10.1053/j.gastro.2011.12.039.

26. Zhao X, Parpart S, Takai A, Roessler S, Budhu A, Yu Z, et al. Integrative genomics identifies YY1AP1 as an oncogenic driver in $\operatorname{EpCAM(+)~AFP(+)~}$ hepatocellular carcinoma. Oncogene. 2015;34(39):5095-104. https://doi. org/10.1038/onc.2014.438.

27. Wang Y, Gao B, Tan PY, Handoko YA, Sekar K, Deivasigamani A, et al. Genome-wide CRISPR knockout screens identify NCAPG as an essential oncogene for hepatocellular carcinoma tumor growth. FASEB J. 2019;33(8): 8759-70. https://doi.org/10.1096/fj.201802213RR.

28. Sun Y, Ji F, Kumar MR, Zheng X, Xiao Y, Liu N, et al. Transcriptome integration analysis in hepatocellular carcinoma reveals discordant intronic miRNA-host gene pairs in expression. Int J Biol Sci. 2017;13(11):1438-49. https://doi.org/10.7150/ijbs.20836.

29. Lu Y, Xu W, Ji J, Feng D, Sourbier C, Yang Y, et al. Alternative splicing of the cell fate determinant Numb in hepatocellular carcinoma. Hepatology. 2015; 62(4):1122-31. https://doi.org/10.1002/hep.27923.

30. Chen S, Fang H, Li J, et al. Microarray analysis for expression profiles of IncRNAs and circRNAs in rat liver after brain-dead donor liver transplantation. Biomed Res Int. 2019;2019:5604843. https://doi.org/10.11 55/2019/5604843.

31. Robin X, Turck N, Hainard A, Tiberti N, Lisacek F, Sanchez JC, et al. pROC: an open-source package for $\mathrm{R}$ and $\mathrm{S}+$ to analyze and compare ROC curves. BMC Bioinformatics. 2011;12(1):77. https://doi.org/10.1186/1471-2105-12-77.

32. Li T, Fan J, Wang B, Traugh N, Chen Q, Liu JS, et al. TIMER: a web server for comprehensive analysis of tumor-infiltrating immune cells. Cancer Res. 2017; 77(21):e108-10. https://doi.org/10.1158/0008-5472.CAN-17-0307.

33. Asplund A, Edqvist PH, Schwenk JM, et al. Antibodies for profiling the human proteome-The Human Protein Atlas as a resource for cancer research. Proteomics. 2012;12(13):2067-77. https://doi.org/10.1002/pmic.2 01100504.

34. Freshour SL, Kiwala S, Cotto KC, Coffman AC, McMichael JF, Song JJ, et al. Integration of the Drug-Gene Interaction Database (DGldb 4.0) with open crowdsource efforts. Nucleic Acids Res. 2021;49(D1):D1144-51. https://doi. org/10.1093/nar/gkaa1084.

35. Griffith M, Griffith OL, Coffman AC, Weible JV, McMichael JF, Spies NC, et al. DGIdb: mining the druggable genome. Nat Methods. 2013;10(12):1209-10. https://doi.org/10.1038/nmeth.2689.

36. Lurje I, Czigany Z, Bednarsch J, Roderburg C, Isfort P, Neumann UP, et al. Treatment strategies for hepatocellular carcinoma " a multidisciplinary approach. Int J Mol Sci. 2019;20(6):1465. https://doi.org/10.3390/ijms20061465.

37. Han J, Han ML, Xing H, Li ZL, Yuan DY, Wu H, et al. Tissue and serum metabolomic phenotyping for diagnosis and prognosis of hepatocellular carcinoma. Int J Cancer. 2020;146(6):1741-53. https://doi. org/10.1002/ijc.32599.

38. Huang CH, Lei KF, Tsang NM. Apoptosis and cell cycle arrest of hepatocellular carcinoma spheroids treated by an alternating electric field Biotechnol Prog. 2019:35(3):e2787. https://doi.org/10.1002/btpr.2787.

39. Nwosu ZC, Battello N, Rothley M, Piorońska W, Sitek B, Ebert MP, et al. Liver cancer cell lines distinctly mimic the metabolic gene expression pattern of the corresponding human tumours. J Exp Clin Cancer Res. 2018;37(1):211. https://doi.org/10.1186/s13046-018-0872-6.

40. Lepri SR, Sartori D, Semprebon SC, Baranoski A, Coatti GC, Mantovani MS. Genistein affects expression of cytochrome P450 (CYP450) genes in hepatocellular carcinoma (HEPG2/C3A) Cell Line. Drug Metab Lett. 2018; 12(2):138-44. https://doi.org/10.2174/1872312812666180709150440.

41. Grant MH, Rodgers EH, Anderson K, Haydon GH, Hayes PC. The effect of serum from liver cancer patients on the growth and function of primary and immortalised hepatocytes. Int J Artif Organs. 2001;24(11):807-13. https://doi.org/10.1177/039139880102401108.

42. Chang BX, You SL, Liu HL, Mao PY, Xin SJ. Establishment of cytochrome P450 3A4 and glutathione S-transferase A1-transfected human hepatoma cell line and functional analysis. Genet Mol Res. 2014;13(3):6949-61. https:// doi.org/10.4238/2014.April.14.11.

43. Tokunaga M, Uto H, Oda K, Tokunaga M, Mawatari S, Kumagai K, et al. Influence of human T-lymphotropic virus type 1 coinfection on the development of hepatocellular carcinoma in patients with hepatitis $C$ virus infection. J Gastroenterol. 2014;49(12):1567-77. https://doi.org/10.1007/s0053 5-013-0928-5.

44. Costa DC, de Oliveira GA, Cino EA, et al. Aggregation and prion-like properties of misfolded tumor suppressors: is cancer a prion disease? Cold Spring Harb Perspect Biol. 2016;8(10):a023614. https://doi.org/10.1101/ cshperspect.a023614.

45. Cascón A, Robledo M. MAX and MYC: a heritable breakup. Cancer Res. 2012; 72(13):3119-224. https://doi.org/10.1158/0008-5472.CAN-11-3891.

46. Audet-Walsh É, Vernier M, Yee T, Laflamme C, Li S, Chen Y, et al. SREBF1 activity is regulated by an AR/mTOR nuclear axis in prostate cancer. Mol Cancer Res. 2018;16(9):1396-405. https://doi.org/10.1158/1 541-7786.MCR-17-0410. 
47. Malumbres M. Cyclin-dependent kinases. Genome Biol. 2014;15(6):122. https://doi.org/10.1186/gb4184.

48. London N, Biggins S. Signalling dynamics in the spindle checkpoint response. Nat Rev Mol Cell Biol. 2014;15(11):736-47. https://doi.org/10.1038/ nrm3888.

49. Zheng HP, Huang ZG, He RQ, Lu HP, Dang YW, Lin P, et al. Integrated assessment of CDK1 upregulation in thyroid cancer. Am J Transl Res. 2019; 11(12):7233-54.

50. Piao J, Zhu L, Sun J, Li N, Dong B, Yang Y, et al. High expression of CDK1 and BUB1 predicts poor prognosis of pancreatic ductal adenocarcinoma. Gene. 2019;701:15-22. https://doi.org/10.1016/j.gene.2019.02.081.

51. Sung WW, Lin YM, Wu PR, Yen HH, Lai HW, Su TC, et al. High nuclear/ cytoplasmic ratio of Cdk1 expression predicts poor prognosis in colorectal cancer patients. BMC Cancer. 2014;14(1):951. https://doi.org/10.1186/1471-24 07-14-951.

52. Zhang R, Shi H, Ren F, Zhang M, Ji P, Wang W, et al. The aberrant upstream pathway regulations of CDK1 protein were implicated in the proliferation and apoptosis of ovarian cancer cells. J Ovarian Res. 2017;10(1):60. https:// doi.org/10.1186/s13048-017-0356-x.

53. Santamaría D, Barrière C, Cerqueira A, Hunt S, Tardy C, Newton K, et al. Cdk1 is sufficient to drive the mammalian cell cycle. Nature. 2007:448(7155):8115. https://doi.org/10.1038/nature06046.

54. Taylor WR, Stark GR. Regulation of the G2/M transition by p53. Oncogene. 2001;20(15):1803-15. https://doi.org/10.1038/sj.onc.1204252.

55. Bayart E, Grigorieva O, Leibovitch $\mathrm{S}$, et al. A major role for mitotic CDC2 kinase inactivation in the establishment of the mitotic DNA damage checkpoint. Cancer Res. 2004;64(24):8954-9. https://doi.org/10.1158/0008-54 72.CAN-04-1613.

56. Wu CX, Wang XQ, Chok SH, Man K, Tsang SHY, Chan ACY, et al. Blocking CDK1/PDK1/ $\beta$-Catenin signaling by CDK1 inhibitor RO3306 increased the efficacy of sorafenib treatment by targeting cancer stem cells in a preclinical model of hepatocellular carcinoma. Theranostics. 2018;8(14): 3737-50. https://doi.org/10.7150/thno.25487.

57. Li L, Huang K, Zhao H, Chen B, Ye Q, Yue J. CDK1-PLK1/SGOL2/ANLN pathway mediating abnormal cell division in cell cycle may be a critical process in hepatocellular carcinoma. Cell Cycle. 2020;19(10):1236-52. https:// doi.org/10.1080/15384101.2020.1749471.

58. Hardwick C, Hoare K, Owens R, Hohn HP, Hook M, Moore D, et al. Molecular cloning of a novel hyaluronan receptor that mediates tumor cell motility. J Cell Biol. 1992;117(6):1343-50. https://doi.org/10.1083/jcb.117.6.1343.

59. Konno D, Shioi G, Shitamukai A, Mori A, Kiyonari H, Miyata T, et al. Neuroepithelial progenitors undergo LGN-dependent planar divisions to maintain self-renewability during mammalian neurogenesis. Nat Cell Biol. 2008;10(1):93-101. https://doi.org/10.1038/ncb1673.

60. Morin X, Jaouen F, Durbec P. Control of planar divisions by the G-protein regulator LGN maintains progenitors in the chick neuroepithelium. Nat Neurosci. 2007;10(11):1440-8. https://doi.org/10.1038/nn1984.

61. Peyre E, Jaouen F, Saadaoui M, Haren L, Merdes A, Durbec P, et al. A lateral belt of cortical LGN and NuMA guides mitotic spindle movements and planar division in neuroepithelial cells. J Cell Biol. 2011;193(1):141-54. https://doi.org/10.1083/jcb.201101039.

62. He R, Zuo S. A robust 8-gene prognostic signature for early-stage non-small cell lung cancer. Front Oncol. 2019;9:693. https://doi.org/10.3389/fonc.2019. 00693.

63. Kang HG, Kim WJ, Kang HG, Chun KH, Kim SJ. Galectin-3 interacts with C/ EBP $\beta$ and upregulates hyaluronan-mediated motility receptor expression in gastric cancer. Mol Cancer Res. 2020;18(3):403-13. https://doi.org/10.1158/1 541-7786.MCR-19-0811.

64. Wang Y, Chen L, Ju L, Qian K, Liu X, Wang X, et al. Novel biomarkers associated with progression and prognosis of bladder cancer identified by co-expression analysis. Front Oncol. 2019;9:1030. https://doi.org/10.3389/ fonc.2019.01030.

65. Yang D, Ma Y, Zhao P, Ma J, He C. Systematic screening of protein-coding gene expression identified HMMR as a potential independent indicator of unfavorable survival in patients with papillary muscle-invasive bladder cancer. Biomed Pharmacother. 2019;120:109433. https://doi.org/10.1016/j. biopha.2019.109433.

66. Kido T, Lau YC. The Y-linked proto-oncogene TSPY contributes to poo prognosis of the male hepatocellular carcinoma patients by promoting the pro-oncogenic and suppressing the anti-oncogenic gene expression. Cell Biosci. 2019;9(1):22. https://doi.org/10.1186/s13578-019-0287-x.
67. Yeung OW, Lo CM, Ling CC, et al. Alternatively activated (M2) macrophages promote tumourgrowth and invasiveness in hepatocellular carcinoma. J Hepatol. 2015;62(3):607-16. https://doi.org/10.1016/j.jhep.2014.10.029.

68. Zou H, McGarry TJ, Bernal T. Identification of a vertebrate sister-chromatid separation inhibitor involved in transformation and tumorigenesis. Science. 1999;285:418-22.

69. Ren $\mathrm{Q}$, Jin B. The clinical value and biological function of PTTG1 in colorectal cancer. Biomed Pharmacother. 2017;89:108-15. https://doi.org/1 0.1016/j.biopha.2017.01.115.

70. Wei C, Yang X, Xi J, et al. High expression of pituitary tumor-transforming gene-1 predicts poor prognosis in clear cell renal cell carcinoma. Mol Clin Oncol. 2015;3(2):387-91. https://doi.org/10.3892/mco.2014.478.

71. Pierconti F, Milardi D, Martini M, Grande G, Cenci T, Gulino G, et al. Pituitarytumour-transforming-gene 1 expression in testicular cancer. Andrologia. 2015:47(4):427-32. https://doi.org/10.1111/and.12283.

72. Repo H, Gurvits N, Löyttyniemi E, Nykänen M, Lintunen M, Karra H, et al. PTTG1-interacting protein (PTTG1IP/PBF) predicts breast cancer survival. BMC Cancer. 2017;17(1):705. https://doi.org/10.1186/s12885-01 7-3694-6.

73. Feng ZZ, Chen JW, Yang ZR, Lu GZ, Cai ZG. Expression of PTTG1 and PTEN in endometrial carcinoma: correlation with tumorigenesis and progression. Med Oncol. 2012;29(1):304-10. https://doi.org/10.1007/s12 032-010-9775-x

74. Liang M, Chen X, Liu W, Li S, Li C, Jiang L, et al. Role of the pituitary tumor transforming gene 1 in the progression of hepatocellular carcinoma. Cancer Biol Ther. 2011;11(3):337-45. https://doi.org/10.4161/cbt.11.3.14102.

75. Fujii T, Nomoto S, Koshikawa K, Yatabe Y, Teshigawara O, Mori T, et al. Overexpression of pituitary tumor transforming gene 1 in HCC is associated with angiogenesis and poor prognosis. Hepatology. 2006;43(6):1267-75. https://doi.org/10.1002/hep.21181.

76. Stoika R, Melmed S. Expression and function of pituitary tumour transforming gene for T-lymphocyte activation. Br J Haematol. 2002;119(4): 1070-4. https://doi.org/10.1046/j.1365-2141.2002.03941.x.

77. Uitdehaag JCM, de Man J, Willemsen-Seegers N, Prinsen MBW, Libouban MAA, Sterrenburg JG, et al. Target residence time-guided optimization on TTK kinase results in inhibitors with potent anti-proliferative activity. J Mol Biol. 2017;429(14):2211-30. https://doi.org/10.1016/j.jmb.2017.05.014.

78. Lim G, Huh WK. Rad52 phosphorylation by Ipl1 and Mps1 contributes to Mps1 kinetochore localization and spindle assembly checkpoint regulation. Proc Natl Acad Sci USA. 2017;114(44):E9261-70. https://doi.org/10.1073/pna S. 1705261114

79. Yamabuki T, Daigo Y, Kato T, Hayama S, Tsunoda T, Miyamoto M, et al. Genome-wide gene expression profile analysis of esophageal squamous cell carcinomas. Int J Oncol. 2006;28(6):1375-84.

80. Stupp R, Mason WP, van den Bent MJ, Weller M, Fisher B, Taphoorn MJB, et al. Radiotherapy plus concomitant and adjuvant temozolomide for glioblastoma. N Engl J Med. 2005;352(10):987-96. https://doi.org/10.1056/ NEJMoa043330.

81. Mizukami Y, Kono K, Daigo Y, Takano A, Tsunoda T, Kawaguchi Y, et al. Detection of novel cancer-testis antigen-specific T-cell responses in TIL, regional lymph nodes, and PBL in patients with esophageal squamous cell carcinoma. Cancer Sci. 2008;99(7):1448-54. https://doi.org/10.1111/j.13497006.2008.00844.x

82. Fan C, Oh DS, Wessels L, Weigelt B, Nuyten DSA, Nobel AB, et al. Concordance among gene-expression-based predictors for breast cancer. N Engl J Med. 2006;355(6):560-9. https://doi.org/10.1056/NEJMoa052933.

83. Xie $Y$, Wang A, Lin J, Wu L, Zhang $H$, Yang $X$, et al. Mps1/TTK: a novel target and biomarker for cancer. J Drug Target. 2017;25(2):112-8. https://doi.org/1 0.1080/1061186X.2016.1258568.

84. Zhu S, Wang W, Clarke DC, Liu X. Activation of Mps1 promotes transforming growth factor-beta-independent Smad signaling. J Biol Chem. 2007;282(25): 18327-38. https://doi.org/10.1074/jbc.M700636200.

85. Huang $H$, Yang $Y$, Zhang $W$, Liu $X$, Yang G. TTK regulates proliferation and apoptosis of gastric cancer cells through the Akt-mTOR pathway. FEBS Open Bio. 2020;10(8):1542-9. https://doi.org/10.1002/2211-5463.12909.

86. Liu X, Liao W, Yuan Q, Ou Y, Huang J. TTK activates Akt and promotes proliferation and migration of hepatocellular carcinoma cells. Oncotarget. 2015;6(33):34309-20. https://doi.org/10.18632/oncotarget.5295.

87. Menyhárt O, Pongor LS, Győrffy B. Mutations defining patient cohorts with elevated PD-L1 expression in gastric cancer. Front Pharmacol. 2019:9:1522. https://doi.org/10.3389/fphar.2018.01522. 
88. Regan-Fendt K, Li D, Reyes R, et al. Transcriptomics-based drug repurposing approach identifies novel drugs against sorafenib-resistant hepatocellular carcinoma. Cancers (Basel). 2020;12:2730.

89. Xu J, Huang F, Yao Z, Jia C, Xiong Z, Liang H, et al. Inhibition of cyclin E1 sensitizes hepatocellular carcinoma cells to regorafenib by mcl-1 suppression. Cell Commun Signal. 2019;17(1):85. https://doi.org/10.1186/s12 964-019-0398-3.

90. Mao X, Du S, Yang Z, et al. Inhibitors of PARP-1 exert inhibitory effects on the biological characteristics of hepatocellular carcinoma cells in vitro. Mol Med Rep. 2017;16(1):208-14. https://doi.org/10.3892/mmr.2017.6568.

91. Pol J, Vacchelli E, Aranda F, Castoldi F, Eggermont A, Cremer I, et al. Trial Watch: Immunogenic cell death inducers for anticancer chemotherapy. Oncoimmunology. 2015;4(4):e1008866. https://doi.org/10.1080/2162402X.2 015.1008866.

\section{Publisher's Note}

Springer Nature remains neutral with regard to jurisdictional claims in published maps and institutional affiliations.

Ready to submit your research? Choose BMC and benefit from:

- fast, convenient online submission

- thorough peer review by experienced researchers in your field

- rapid publication on acceptance

- support for research data, including large and complex data types

- gold Open Access which fosters wider collaboration and increased citations

- maximum visibility for your research: over $100 \mathrm{M}$ website views per year

At $\mathrm{BMC}$, research is always in progress.

Learn more biomedcentral.com/submissions 